\title{
TEM analysis of the internal structures and mineralogy of Asian dust particles and the implications for optical modeling
}

\author{
G. Y. Jeong ${ }^{1}$ and T. Nousiainen ${ }^{2}$ \\ ${ }^{1}$ Department of Earth and Environmental Sciences, Andong National University, Andong 760-749, Republic of Korea \\ ${ }^{2}$ Finnish Meteorological Institute, P.O. Box 503, 00101, Helsinki, Finland \\ Correspondence to: G. Y. Jeong (jearth@anu.ac.kr)
}

Received: 17 January 2014 - Published in Atmos. Chem. Phys. Discuss.: 12 March 2014

Revised: 15 May 2014 - Accepted: 2 June 2014 - Published: 16 July 2014

\begin{abstract}
Mineral dust interacts with incoming/outgoing electromagnetic radiation in the atmosphere. This interaction depends on the microphysical properties of the dust particles, including size, mineral composition, external morphology, and internal structure. Ideally all of these properties should be accounted for in the remote sensing of dust, the modeling of single-scattering properties, and radiative effect assessment. There have been many reports on the microphysical characterizations of mineral dust, but no investigations of the internal structures of individual dust particles. We explored the interiors of Asian dust particles using the combined application of focused ion beam thin-slice preparation and high-resolution transmission electron microscopy. The results showed that individual dust particles consisted of numerous mineral grains, which were organized into several types of internal structure: single and polycrystalline cores of quartz, feldspars, calcite, and amphibole often with oriented clay coatings; individual clay agglomerates of nano-thin clay platelets showing preferred to random orientations common with coarser mineral inclusions; and platy coarse phyllosilicates (muscovite, biotite, and chlorite). Micron to submicron pores were scattered throughout the interior of particles. Clays in the coatings and agglomerates were dominated by nano-thin platelets of the clay minerals of illite-smectite series including illite, smectite, and their mixed layers with subordinate kaolinite and clay-sized chlorite. Submicron iron oxide grains, dominantly goethite, were distributed throughout the clay agglomerates and coatings. Unlike the common assumptions and simplifications, we found that the analyzed dust particles were irregularly shaped with birefringent, polycrystalline, and polymineralic heterogeneous compositions. Accounting for this structural and mineralogical
\end{abstract}

makeup may improve the remote sensing retrieval of dust and the evaluation of radiation effects, but will also require sophisticated single-scattering modeling. In particular, the observed internal structures of dust particles such as clay coatings, preferred orientation, embedded grains in clays, and pores, have the potential to considerably impact on the light scattering by dust particles. The distribution and size of structural components with contrasting dielectric properties, such as iron oxides, should also be explicitly accounted for.

\section{Introduction}

Mineral dust interacts with atmospheric incoming/outgoing electromagnetic radiation, contributing to Earth's radiative balance (Sokolik and Toon, 1996; Tegen and Lacis, 1996; Posfai and Molnar, 2012; Formenti et al., 2011). The net radiative effect of natural and anthropogenic mineral dust, sulfate, and organic carbon aerosols is considered to be negative (Forster et al., 2007). In the case of mineral dust, Forster et al. (2007) reported net direct-radiative effects ranging from -0.56 to $+0.1 \mathrm{~W} \mathrm{~m}^{-2}$. However, regional observations showed that the direct radiative effect of dust can vary considerably, ranging from $-130 \mathrm{~W} \mathrm{~m}^{-2}$ over the ocean off the coast of West Africa (Haywood et al., 2003) to $+50 \mathrm{~W} \mathrm{~m}^{-2}$ over land in North Africa (Haywood et al., 2005). The uncertainty associated with the net radiative effect of dust is large (Forster et al., 2007) and is attributed to dust particles' microphysical properties such as particle size, shape, and composition; including inhomogeneity and common birefringence, as well as uncertainties in spatiotemporal global distributions (Nousiainen, 2009). Remote sensing provides 
detailed information on the atmospheric loading, distribution, migration, particle size, and even some mineralogical properties of dust (Seinfeld et al., 2004; Chou et al., 2008; Kim et al., 2008; McKendry et al., 2008; Chudnovsky et al., 2009; Chen et al., 2011; Haywood et al., 2011; Lenoble et al., 2013). Therefore, it would be ideal for all microphysical properties to be faithfully accounted for when computing the dust's single-scattering properties that are applied to radiative effect estimations and remote-sensing retrievals (Sokolik et al., 2001; Forster et al., 2007). For example, an early inversion algorithm for AERONET (Aerosol Robotic Network) developed by Dubovik and King (2000) assumed homogeneous isotropic spherical particles. However, later applications of the spheroidal particles allowed for more accurate fitting of observed radiation intensity and polarization (Dubovik, 2006).

Extensive microphysical characterizations have been performed for single dust particles to determine their chemical composition (Okada et al., 1990; Anderson et al., 1996; Ro et al., 2005; Gao et al., 2007; Kandler et al., 2007), mineralogical composition (Jeong, 2008; Jeong et al., 2014), and particle size distributions (Reid et al., 2003). Microphysical properties are determined by the laboratory analyses of dust samples on a filter or the real-time analysis of particles through means such as optical particle counting and single particle mass spectrometry, to determine size, morphology, and chemical or mineralogical types (Kulkarni et al., 2011, and references therein). However, a "single" particle is rarely a single crystal or mineral, but commonly polycrystalline and polymineralic (Falkovich et al., 2001; Jeong, 2008; Jeong et al., 2014). Thus, the microphysical data obtained from "single" particles are often the result of the numerous mineral grains, composed of different mineral species. Nevertheless, dust particles have usually been grouped into several chemical and mineralogical types based on the resultant properties (Anderson et al., 1996; Gao et al., 2007; Jeong et al., 2014). However, despite the abundant reports, the microphysical properties of individual dust particles have not been fully resolved. While information about the chemistry, mineralogy, external morphology, and size distribution of "single" particles are needed when modeling the single-scattering properties of mineral dust, they do not offer information about the internal structure of the particles. All of this information is needed to yield the true single-scattering properties. Hereafter, we will denote the particle size, shape, composition and internal structure as microphysical properties, which are input to single-scattering models that produce the optical (single-scattering) properties as output.

The geometric characteristics of the internal structure of single dust particles and the varying dielectric properties of the structural components are largely unknown key factors in the evaluation of dust-particle single-scattering properties. For example, Vilaplana et al. (2006) found that the linear polarization of scattered radiation has fundamentally different size dependence and characteristics in terms of absorb- ing dust particles with or without internal structure. Likewise, Nousiainen et al. (2011a) observed that the singlescattering properties of spheroids with empty cavities could not be mimicked by solid spheroids of varying sizes, shapes and compositions, suggesting fundamentally different singlescattering properties as a result of particle porosity. Similarly, a modeling study by Nousiainen et al. (2011b) found that, for irregular ice crystals, the internal structure had the greatest potential of all the parameters considered to change singlescattering properties. Nousiainen et al. (2003) and Muinonen et al. (2009) found that internal structure, assumed in their studies to be a random structure in the absence of observational data, is potentially quite significant for the singlescattering properties of dust particles much larger than the wavelength. In contrast to considerable efforts expended to investigate how the single-scattering properties of dust particles depend on particle shape (e.g., Nousiainen, 2009; Nousiainen and Kandler, 2014), relatively little attention has been paid to effects arising from internal structures. Undoubtedly the main reasons for this are the general lack of information regarding the microphysical characteristics of the particle interiors and the limitations imposed by the computational methods needed to solve single-scattering properties.

Iron oxides of complex refractive indices with large real and imaginary parts contribute greatly to the singlescattering properties of mineral dust (Sokolik and Toon, 1999; Lafon et al., 2006; Koven and Fung, 2006; Balkanski et al., 2007; Derimian et al., 2008; Moosmüller et al., 2012). However, calculations have shown that their contributions vary greatly depending on assumptions about the mixing state and mineralogy of iron oxides (Sokolik and Toon, 1999; Lafon et al., 2006). Direct analyses of mixing state and mineralogy were rarely performed for individual particles (Díaz-Hernández and Párraga, 2008; Conny, 2013; Jeong et al., 2014). Díaz-Hernández and Párraga (2008) observed the internal structures of the iberulite, an aggregate of Saharan dust particles wetted in raindrops using a back-scattered electron imaging of polished section. They presented a part of transmission electron microscopic images of ultramicrotome section. Conny (2013) applied focused ion beam (FIB) technique to expose the cross sections of urban dust particles which were analyzed by scanning electron microscopy (SEM). Adler et al. (2013) applied FIB-SEM to analyze the internal pores of organic aerosol. Jeong et al. (2014) combined SEM and transmission electron microscopy (TEM) to characterize the physical and chemical properties of Asian dust particles. A combined application of FIB and TEM is the best method in the high-resolution analysis of mixing state and mineralogy of dust particles. Despite some attempts, almost no investigations dedicated to the systematic analysis of the internal structures and mineralogical makeup of individual dust particles have been published so far. Consequently, the impact of these factors on the dust's single-scattering properties and radiative effects, as well as on the interpretation of remote sensing data, remains largely uninvestigated, 
or has otherwise been based on hypothetical models of internal structure (Nousiainen, 2009, and references therein). Yet, these are clearly important factors to consider in radiationrelated applications.

In this study, we explored the interiors of individual Asian dust particles using high-resolution TEM. Electrontransparent thin slices were prepared for TEM analysis using an FIB technique. We report the structural and mineralogical details of the Asian dust particles, and discuss the implications of our findings for single-scattering properties and, consequently, for remote sensing and radiative effects.

\section{Samples and method}

Asian dust storms occurring in the Gobi desert affect east Asia in spring (March-May) season. Dust-laden air mass moves eastward and crosses Korea, Japan, and North Pacific Ocean. Almost real time satellite remote sensing data of Asian dust are uploaded with $\mathrm{PM}_{10}$ level on the website of Korea Meteorological Administration. Dust sampler was operated for several days after dust storm outbreak was identified in the Gobi desert from the remote sensing data. $\mathbf{P M}_{10}$ data indicate the arrival time of the Asian dust around the sampling site. Dust particles were collected on a borosilicate glass-fiber filter using a thermo-scientific high-volume total suspended particulate (TSP) sampler around Seoul on 31 March 2012 and in Andong, Korea, on 17 March 2009. Meteorological, mineralogical, and physical properties of the 2012 dust were previously reported by Jeong et al. (2014). Satellite dust-index images (National Meteorological Satellite Center, 2014) showed that the source of both the 2012 and 2009 dust was the Gobi desert, situated around northern China and southern Mongolia.

The individual dust particles on the filter were preliminarily examined using a TESCAN LMU VEGA SEM, equipped with an IXRF energy dispersive X-ray spectrometer. The SEM analysis showed that most dust particles were not tightly agglomerated but separated each other. Individual dust particles were able to be identified on the filter. Since the unstable dust particles lying on the porous filter were not suitable for FIB milling, they were transferred onto a conductive carbon adhesive tape. An SEM stub covered with carbon tape was lightly touched onto the filter surface. After applying a thin platinum coating for $60 \mathrm{~s}$ for conduction, the predominant mineralogy of the dust particles was analyzed using energy dispersive X-ray spectrometry (EDXS). High-resolution SEM images were acquired with a JEOL JSM 6700F field emission gun (FEG) SEM.

Dust particles for FIB sample preparation were selected on the basis of the predominant particle mineralogy and morphology determined by EDXS and FEG SEM. We selected only individual dust particles spaced sufficiently from other particles, excluding particles that are too close, forming a cluster. The SEM stub was placed on a SMI3050TB FIB instrument for preparing thin slices of approximately (512) $\times(5-6) \mu \mathrm{m}^{2}$ area and about $100 \mathrm{~nm}$ in thickness. Carbon was first deposited on the target particle in a thickness of $\sim 1 \mu \mathrm{m}$ to protect the loose and porous agglomerates of fine mineral grains from ion beam damage and spalling, and then a gallium ion beam was sputtered to cut one thin slice from each individual dust particle. Deposited carbon was amorphous, and normally did not affect the interior of particle. However, in some case, carbon entered into and filled large pore probably connected to the surface (Fig. 3c). Altogether 35 FIB slices were prepared from 35 dust particles, and analyzed by TEM. Of these slices, 26 had a good flatness and a wide area, which was sufficient for the TEM analysis. However, only a limited analysis of a small area was possible in nine slices, which had broken due to the cleavage of minerals or loose agglomeration during the handling of micron-size slices in the FIB instrument or in the TEM chamber. Some of the slices were not suitable for lattice fringe imaging due to their thickness. The FIB slices were imaged using three microscopes: a JEOL JEM 2100F FEG STEM at $200 \mathrm{kV}$ and a JEOL JEM 3010 at $300 \mathrm{kV}$ for high-resolution imaging, and a JEOL JEM 2010 TEM at $200 \mathrm{kV}$ equipped with an Oxford energy dispersive X-ray spectrometer for EDXS analysis. TEM images were recorded using a Gatan digital camera, and processed with Gatan DigitalMicrograph ${ }^{\circledR}$.

Combined application of TEM and FIB slicing is the best method imaging the internal structures of dust particles. Unfortunately, the FIB slicing cannot be applied to a large set of dust particles because it is expensive and needs complex operation, particularly for irregular, weak agglomerate particles. However, the 35 particles were carefully selected from thousands of particles which had been already classified into minerals and mineral groups based on their morphological and chemical characterization by extensive SEM and EDXS analyses like in Jeong (2008) and Jeong et al. (2014). In addition, the mineralogical features of the Asian dust varied little through different events over many years (Jeong, 2008; Jeong et al., 2014). Thus, the internal structures presented here are representative of the Asian dust particles.

Artifacts reported in the FIB slicing are surface amorphization, Ga contamination, and curtain effect (Ishitani et al., 2004; Kato, 2004; Mayer et al., 2007). Our FIB slices showed sufficiently clear TEM images without the destruction of microstructural details and lattice fringes, indicating that surface amorphization was restricted in very thin surface region, and had little influence on the image quality. Ga was only detected around the boundary between carbon deposit and dust particle by EDXS analysis, but not within the particle interior. Curtain effects (stripes of light and dark contrast) arising from topography and phase property (pores, mineral chemistry, and density) were observed in some of the TEM images (e.g., Figs. 5c, 7d, 9c, 10c, and 11d), with no significant degradation of image quality. Finally, pores found in the particle interiors were not formed by FIB milling. In traditional ion milling, Ar ions bombard the sample surface 


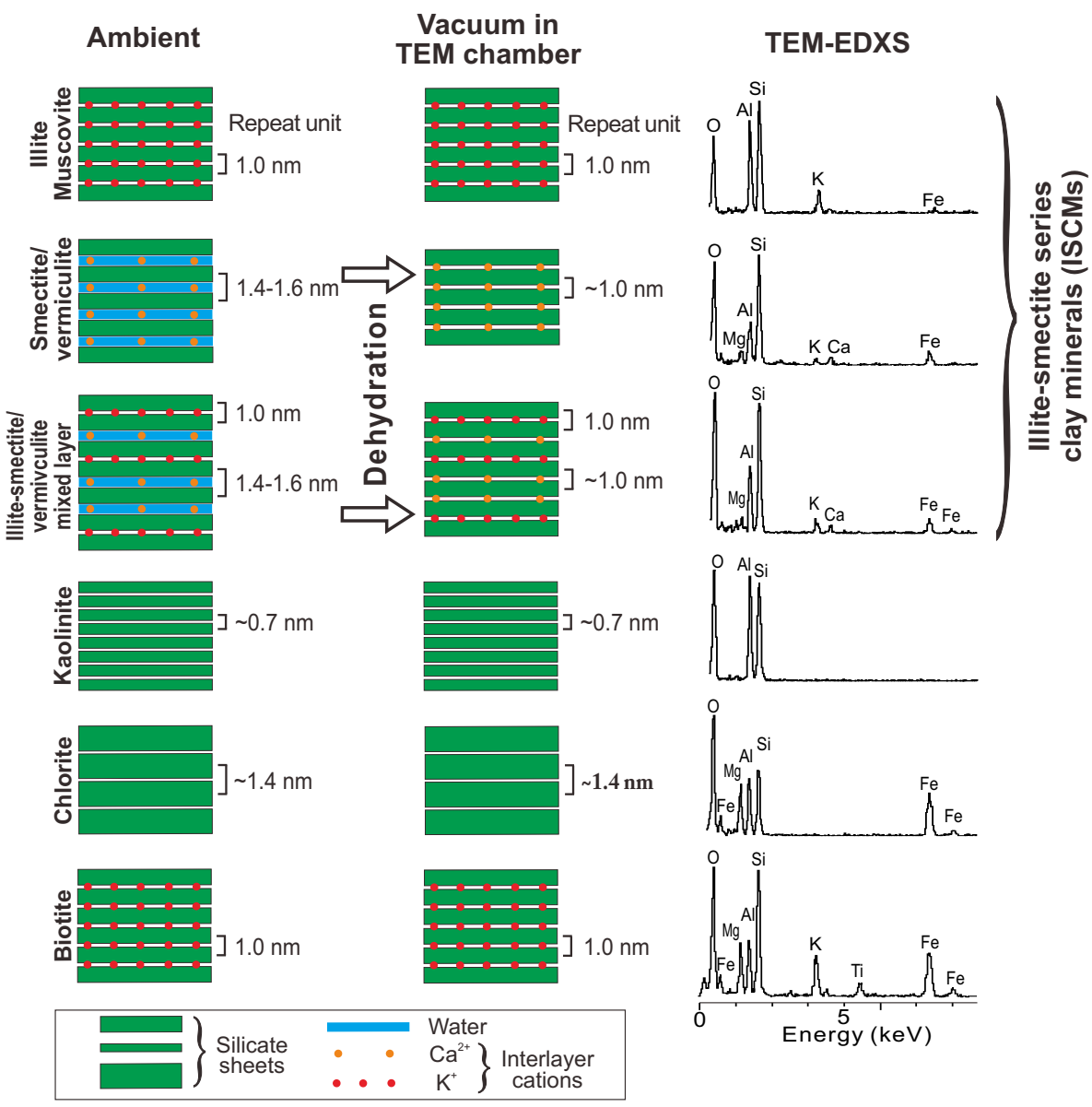

Figure 1. Identification criteria of clay minerals based on the spacing of repeat units measured from a TEM lattice fringe image (left two columns) and EDXS spectra (right column). Repeated stacking of silicate sheets in clay minerals viewed along the crystallographic a-b plane.

at higher angles, making a hole in the center. The thin edge around the hole is then analysed by TEM. Thus, preferred erosion may occur along the weak parts of the samples such as grain boundary and poorly crystalline phases, resulting in pore-like features around a large center hole. However, in FIB milling, $\mathrm{Ga}$ ions are bombarded almost parallel to the sample surface, without forming artifact pores in most cases. This is one of the most important advantages of FIB milling of geological samples compared to the traditional Ar ion milling. Our TEM images discussed later, in Sect. 3.1, preserve the large and small pores of delicate shapes, all of which are reasonably interpreted on the basis of grain agglomeration and mineral growth/dissolution.

Mineral identification was based on lattice fringes and EDXS chemical compositions. General chemical formulas of minerals identified in the Asian dust examined in this study are provided in the Supplementary Table 1 . The identification of non-phyllosilicate and relatively coarse phyllosilicate minerals (muscovite, biotite, and chlorite) was straightforward, but that of nano-thin phyllosilicates (clay minerals) was difficult. The lattice fringes of clay minerals parallel to basal plane were recorded normally above the magnification of $\times 200000$. The identification of clay minerals was based on the spacings of lattice fringes corresponding to the spacing of repeat units of the crystal structures: $1.0 \mathrm{~nm}$ for illite, $\sim 1.0 \mathrm{~nm}$ for smectite and vermiculite, $\sim 7.0 \mathrm{~nm}$ for kaolinite, and $\sim 1.4 \mathrm{~nm}$ for chlorite (Fig. 1). Kaolinite and chlorite were directly identified from their EDXS and lattice fringes (Fig. 1). However, illite, smectite, vermiculite, and illite-smectite (vermiculite) mixed layers could not be positively distinguished from each other because smectite $(1.4-1.6 \mathrm{~nm}$ unit layers in hydrated state) was dehydrated and contracted under the high vacuum of the TEM chamber, showing $\sim 1.0 \mathrm{~nm}$ lattice fringes similar to those of illite (1.0 nm lattice fringe) (Fig. 1) (Peacor, 1992). EDXS can be used for identifying illite and smectite with interlayer cations $\mathrm{K}$ and $\mathrm{Ca}$, respectively. Illite could form a thick plate and be positively identified from the clear $1.0 \mathrm{~nm}$ lattice fringe and high $\mathrm{K}$ and $\mathrm{Al}$ contents. However, illite and smectite platelets are normally very thin, consisting of only a few repeat units. 

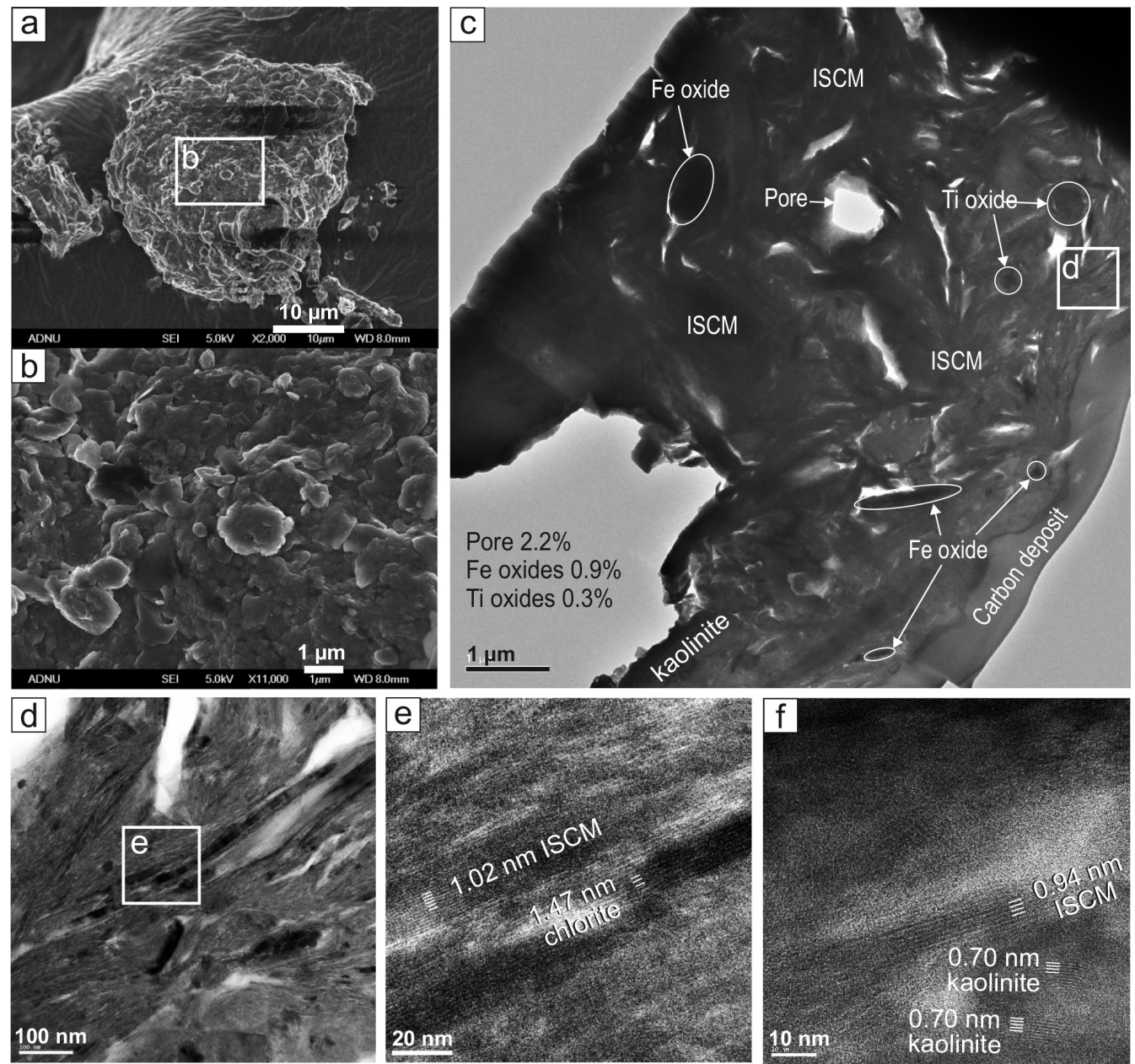

Figure 2. Clay-rich dust particle \#1 from 2012 Asian dust. (a) SEM image of the dust particle. (b) SEM image of the particle surface magnified from the box in (a). (c) Overall TEM image of FIB slice prepared from the particle in (a). (d) TEM image magnified from the box in (c). (e) TEM lattice fringe image of ISCM and chlorite. (f) TEM lattice fringe image of ISCM and kaolinite.

They cannot be separately analyzed using EDXS, even when using an electron microbeam that is as small as possible. Additionally, mixed layering of illite and smectite is common in the soil and geological environments (Weaver, 1989; Środon, 1999). Therefore, in practice, we cannot distinguish between nano-thin illite and smectite. To avoid over-interpretation, nano-thin platelets of clay minerals showing $\sim 1.0 \mathrm{~nm}$ lattice fringes with varying $\mathrm{K}$ and $\mathrm{Ca}$ contents were grouped into illite-smectite series clay minerals (ISCMs). ISCMs are likely nano-scale mixtures of nano-thin platelets of illite, smectite, and illite-smectite mixed layers.

\section{Results and discussion}

In what follows, we will first present the results of our TEM analyses of dust particles. Schematic models for the common structural types observed will then be proposed. Finally, we will discuss the possible implications of the structural fea- tures on dust optical modeling and on climate and remote sensing applications. Detailed TEM data of 12 dust particles are presented in Figs. 2-13. TEM data of other 14 particles are summarized in Supplementary Fig. 1.

\subsection{TEM observations}

\subsubsection{Clay-rich particles}

TEM data for three clay-rich particles showing different internal structures are presented here because they are the most abundant particle type in Asian dust (Jeong, 2008; Jeong et al., 2014). SEM images of the clay-rich dust particle \#1 show a rough surface composed of submicron clay grains (SEM images in Fig. 2a, b). Low-magnification TEM images of the FIB slice prepared from the particle in Fig. 2a show an agglomerate of randomly oriented platelets of clay minerals, which are tightly interlocked with each other (Fig. 2c). EDXS analyses suggest that the clays are mainly ISCMs 

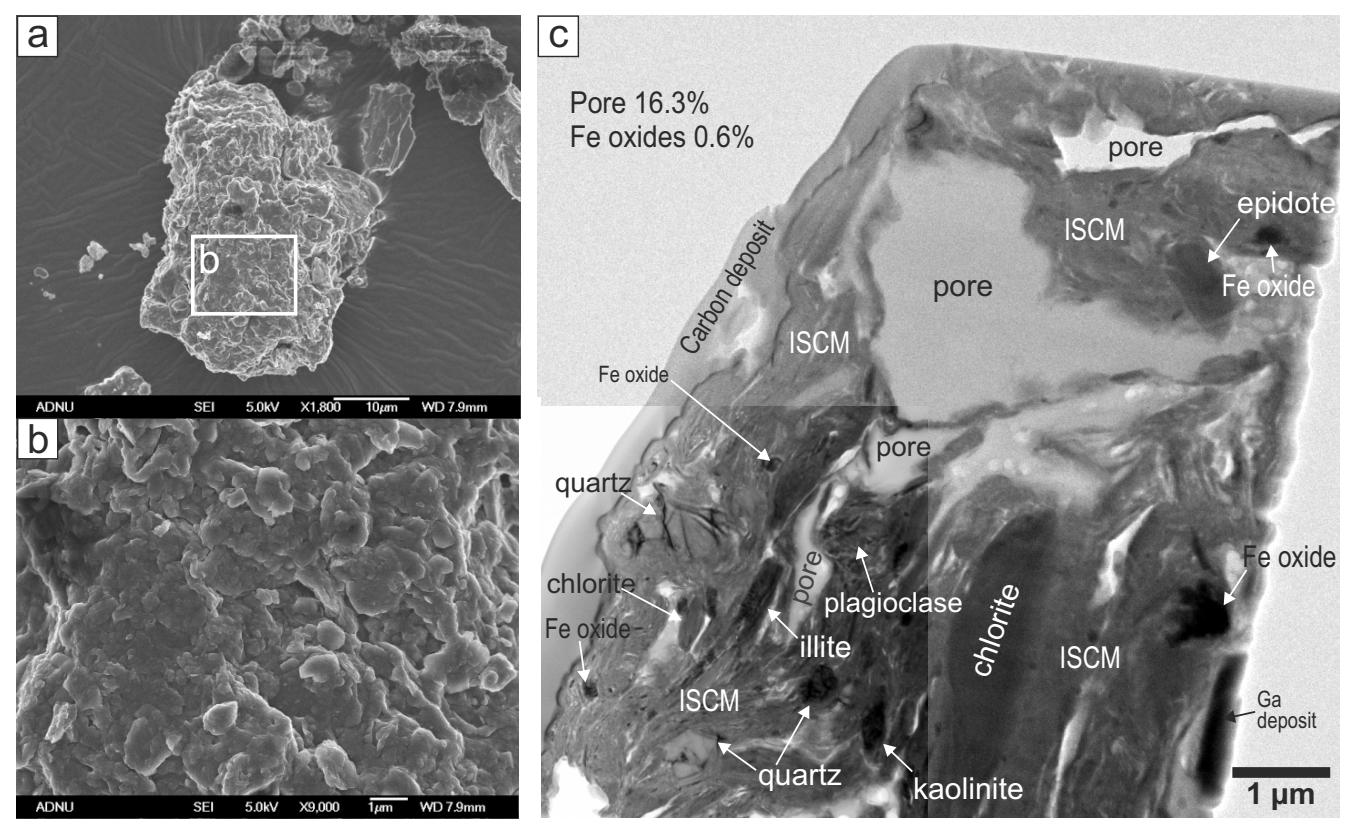

Figure 3. Clay-rich dust particle \#2 from 2012 Asian dust. (a) SEM image of the dust particle. (b) SEM image of the particle surface magnified from the box in (a). (c) Overall TEM image of the FIB slice prepared from the particle in (a). Pores are filled with carbon deposited prior to slicing.

with some chlorite and kaolinite. Minor quantities of submicron iron and titanium oxide grains are also randomly distributed in the clay matrix (Fig. 2c). Confirmation of the specific mineral species of the iron and titanium oxides was not possible because the quality of lattice fringes was poor due to the large slice thickness. The areal fractions of these oxides in Fig. 2c are approximately 0.9 and $0.3 \%$, respectively. High-magnification TEM images of the clay show loose, disrupted, and nano-thin clay platelets (Fig. 2d-f). Lattice fringes confirm ISCMs (Fig. 2e-f) intermixed with coarser platelets of chlorite (Fig. 2e) and kaolinite (Fig. 2f). There are many pores (total $2.2 \%$ ) of approximately $1 \mu \mathrm{m}$ in diameter (Fig. 2c). Thin lenticular pores may have been formed through the dehydration of subparallel platelets of expandable clay minerals such as smectite in the high vacuum TEM chamber (Peacor, 1992). However, some of the circular pores (arrow in Fig. 2c) are unlikely to have formed in this way by dehydration. They may have been formed by soil process, particularly repeated cycles of wetting-drying and freezingsawing in the dry and cool sources of Asian dust.

The clay-rich agglomerate particle \#2 also displays a rough surface with micron-to-submicron-sized clay grains (Fig. 3a, b). The mineral grains are at least to some degree preferentially oriented. A TEM image of the slice reveals a large pore size of approximately $4 \mu \mathrm{m}$ (Fig. 3c), which is certainly not the result of the contraction of expandable clay minerals. The pores $(16.3 \%)$ are now filled with carbon that was deposited during FIB slicing. The clay matrix is dominated by nano-thin ISCM platelets embedded with rather large packets of chlorite, kaolinite, and discrete illite (Fig. 3c). Non-phyllosilicate particles of quartz, plagioclase, epidote, and iron oxides were also scattered within the clay matrix. Iron oxides are present in minor quantities $(0.6 \%)$ and approximately $200 \mathrm{~nm}$ in size.

The clay-rich agglomerate particle \#3 (Fig. 4a, b) has rough surface exhibiting submicron clay particles. The lowmagnification TEM image shows highly oriented fabrics (Fig. 4c). Magnified images (Fig. 4d, e) reveal submicron particles of quartz, plagioclase, K-feldspar, biotite, discrete illite, and titanium oxide, the long axes of which were oriented conformably with the fine matrix of oriented nano-thin ISCM platelets. The platelets are generally curved and subparallel to each other (Fig. 4f). Both the lattice fringe imaging and EDXS confirmed that ISCMs are the dominant clay minerals (Fig. 4f). Some long, thin lenticular pores are certainly attributable to the contraction of expandable clay minerals under the vacuum (Fig. 4c). However, the other pores were not formed by dehydration (arrow in Fig. 4c).

The external morphology and surface features of the three clay-rich particles are similar. However, a TEM analysis of the slices shows that the large differences in fabrics depend on the array pattern and sizes of phyllosilicate platelets, pores, and coarser inclusions. Nano-thin ISCM-rich clays are the major constituents of the matrix, scattered with submicron iron and titanium oxides. 

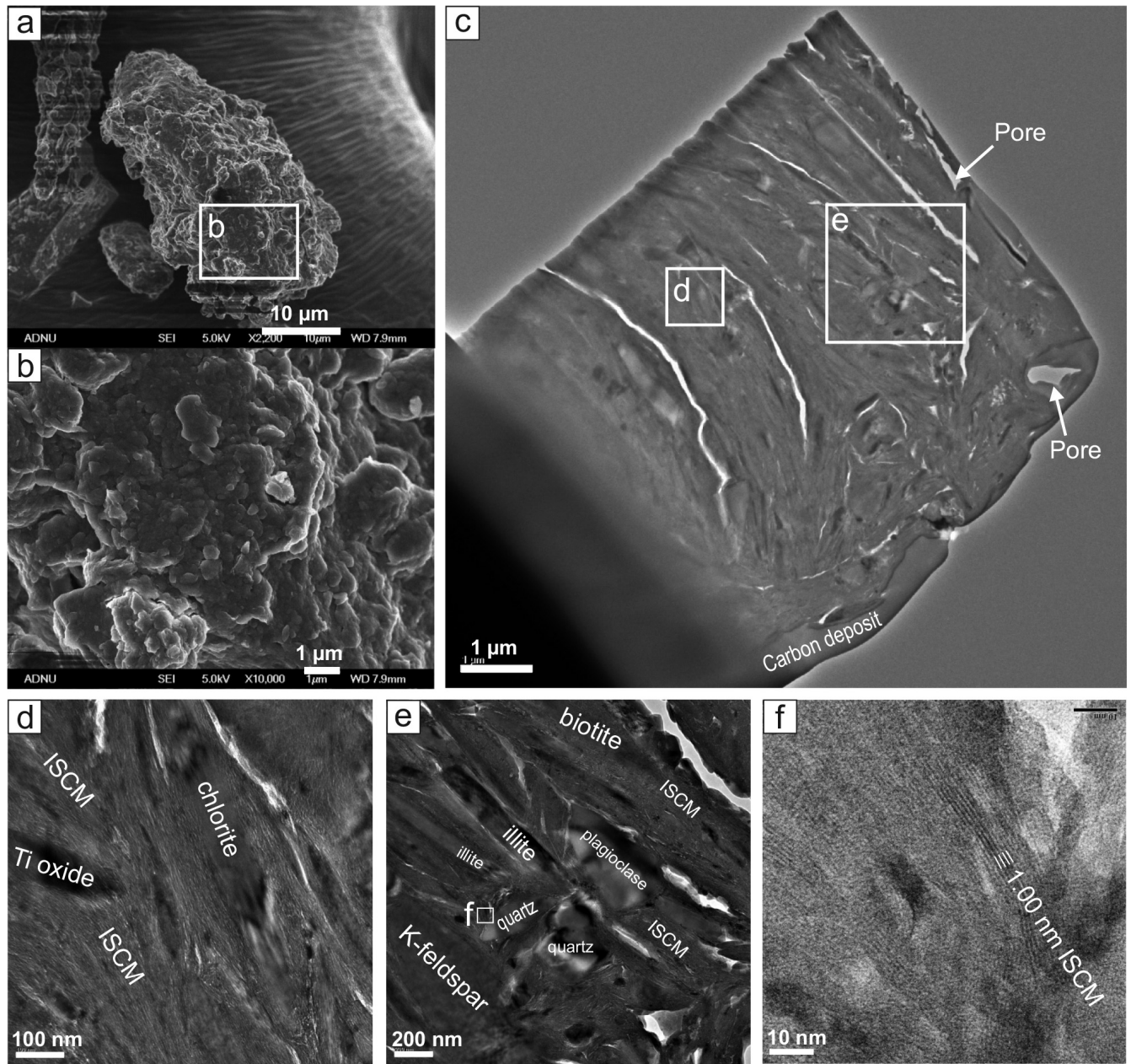

Figure 4. Clay-rich dust particle \#3 from 2012 Asian dust. (a) SEM image of the dust particle. (b) SEM image of the particle surface magnified from the box in (a). (c) Overall TEM image of the FIB slice prepared from the particle in (a). (d, e) TEM images magnified from the boxes in (c). (f) TEM lattice fringe image of ISCMs.

\subsubsection{Quartz-rich particles}

A quartz-rich particle in the SEM images (Fig. 5a, b) has an irregular shape and a rough surface coated with submicron clay plates. A low-magnification TEM image of the slice prepared from the particle (Fig. 5c) reveals a quartz grain wrapped with thin coatings $(\sim 200 \mathrm{~nm}$ thick $)$, which are composed of oriented submicron platelets of clay minerals (Fig. 5d, e). The clay minerals are mostly ISCMs, based on the $\sim 1.0 \mathrm{~nm}$ lattice fringe and the EDXS (Fig. 5f). Submicron goethite grains identified from the lattice fringe and EDXS are scattered within the clay coatings (Fig. 5g).

Another quartz-rich particle shown in the SEM images (Fig. 6a, b) also has an irregular morphology and a surface coated with micron to submicron clay platelets. A TEM image of the slice prepared from the particle reveals a thick clay coating ( $\sim 1 \mu \mathrm{m}$ thick) with a quartz core (Fig. $6 \mathrm{c}$ ). The coating is primarily composed of nano-thin platelets of clay minerals showing a high degree of preferred orientation (Fig. 6d).
Submicron quartz particles were also found in the clay coatings (Fig. 6d). Magnified images show subparallel, chaotic arrangement of nano-thin ISCM platelets $(1-10 \mathrm{~nm}$ thick; Fig. 6d-f). The lattice fringe shows that the clay minerals are mostly ISCMs (Fig. 6e) with some chlorite (Fig. 6f). The ISCMs were tightly adhered to the surface of the quartz core (Fig. 6e). Fine iron oxides were also found within the clay coating, but were not common (Fig. 6d).

\subsubsection{Plagioclase-rich particle}

A plagioclase-rich particle shown in the SEM images (Fig. 7a, b) has an irregular shape with surface clay coatings. The slice prepared from the particle reveals clay coatings of $\sim 0.2$ to $1 \mu \mathrm{m}$ thick (Fig. $7 \mathrm{c}$ ). Magnified images of the coating show nano-thin platelets of clay minerals oriented along the plagioclase surface (Fig. 7d, e). A submicron quartz grain is embedded in the clay coating (Fig. $7 \mathrm{~g}$ ) and pores are found around the quartz grain. The lattice fringe images 

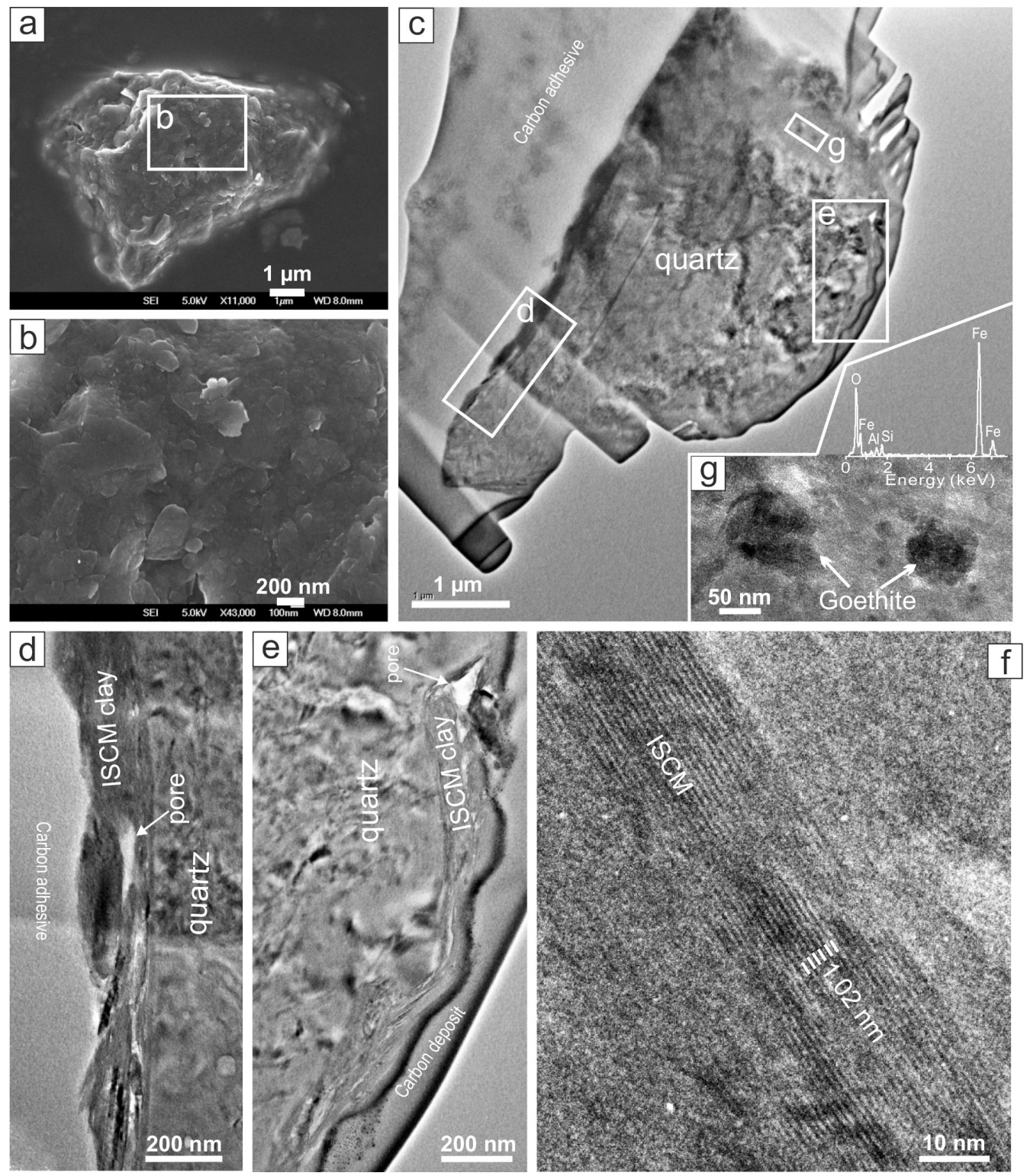

Figure 5. Quartz-rich dust particle \#1 from 2009 Asian dust. (a) SEM image of the dust particle. (b) SEM image of the particle surface magnified from the box in (a). (c) Overall TEM image of the FIB slice prepared from the particle in (a). (d, e) TEM images magnified from the box in (c). (f) TEM lattice fringe image of ISCMs. (g) Goethite spheres magnified from the box in (c) with the EDXS pattern of goethite.

show that most of the clay platelets are ISCMs with some chlorite $(\sim 1.4 \mathrm{~nm})$ and kaolinite $(0.7 \mathrm{~nm})$ (Fig. $7 \mathrm{e}, \mathrm{f}, \mathrm{h})$. In the cavity inside the plagioclase, short tubes of halloysite are found attached to the cavity wall (Fig. 7i). Halloysite is a kaolin-group clay mineral, which typically forms during the chemical weathering of plagioclase (Jeong and Kim, 1993). The cavity in the plagioclase core was formed by dissolution during weathering in the source soils.

\subsubsection{Calcite-rich particle}

The particle in the SEM images (Fig. 8a, b) is calcite-rich with a clay surface coating. The slice made from the particle reveals a polycrystal consisting of micron to submicronsized calcite crystals (Fig. 8c-e). The calcite polycrystal was coated with thin $(<200 \mathrm{~nm}$ ) ISCM clay layers (Fig. 8d, e).

\subsubsection{Amphibole-rich particle}

An amphibole-rich particle is encrusted with submicron clay platelets (Fig. 9a, b). A TEM image of a slice prepared from the particle reveals that the surface of the amphibole is coated 

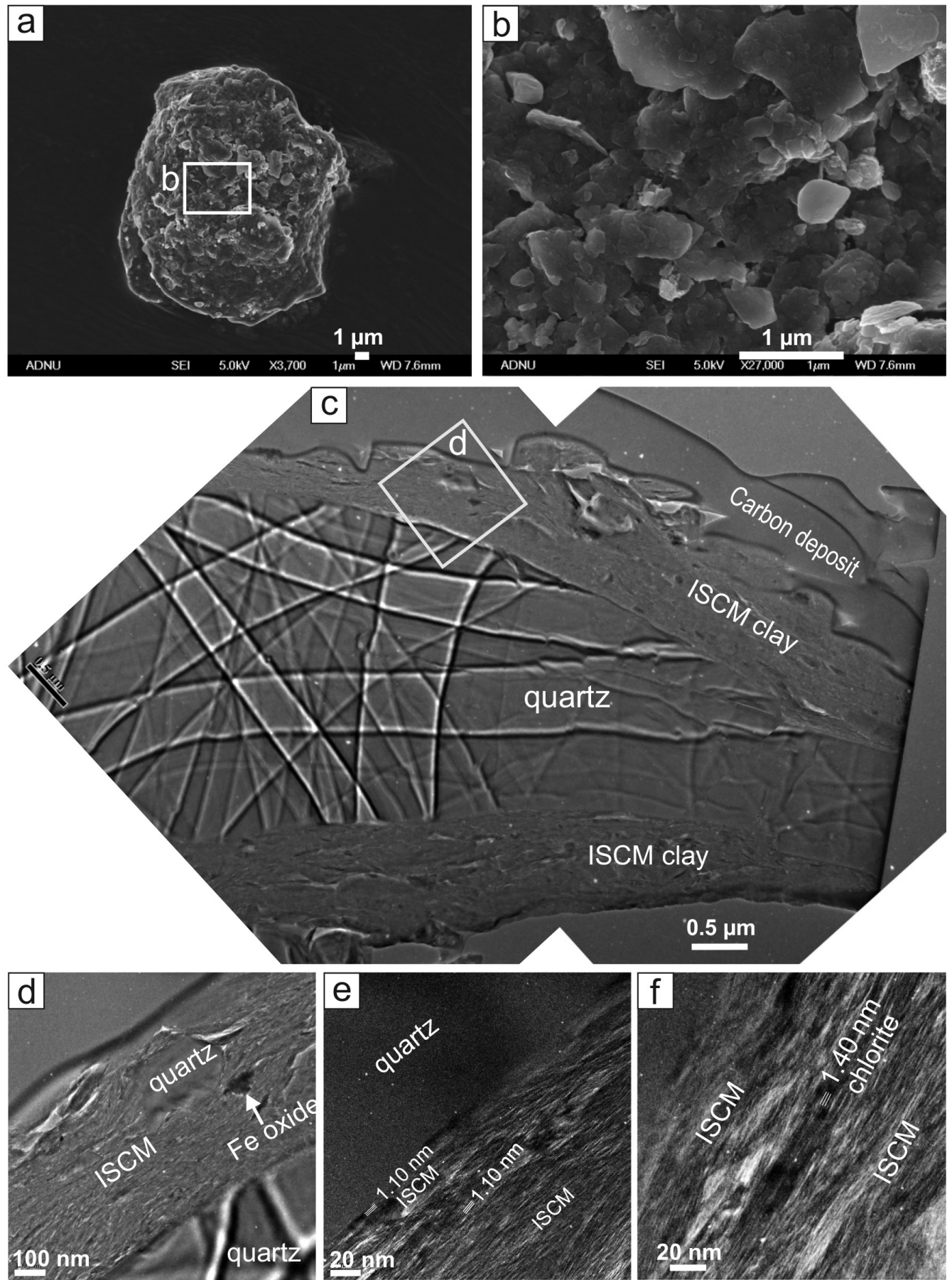

Figure 6. Quartz-rich dust particle \#2 from 2009 Asian dust. (a) SEM image of the dust particle. (b) SEM image of the particle surface magnified from the box in (a). (c) Overall TEM image of the FIB slice prepared from the particle in (a). (d) TEM image magnified from the box in (c). (e) TEM lattice fringe image of ISCMs. (f) TEM lattice fringe image of ISCM and chlorite.

with subparallel stacks of ISCM platelets subordinately with chlorite, quartz, calcite, and titanium oxide (Fig. 9d). Submicron pores were distributed within the coatings, particularly around the larger grains such as chlorite and calcite (Fig. 9d). Lattice fringes show that the dominant clay minerals are ISCMs (Fig. 9e).

\subsubsection{Biotite-rich particle}

SEM images (Fig. 10a, b) reveal a biotite flake coated with submicron clay plates. A slice perpendicular to the plate shows long lenticular iron oxide grains formed along the biotite layers (Fig. 10d). The iron oxide was identified as 

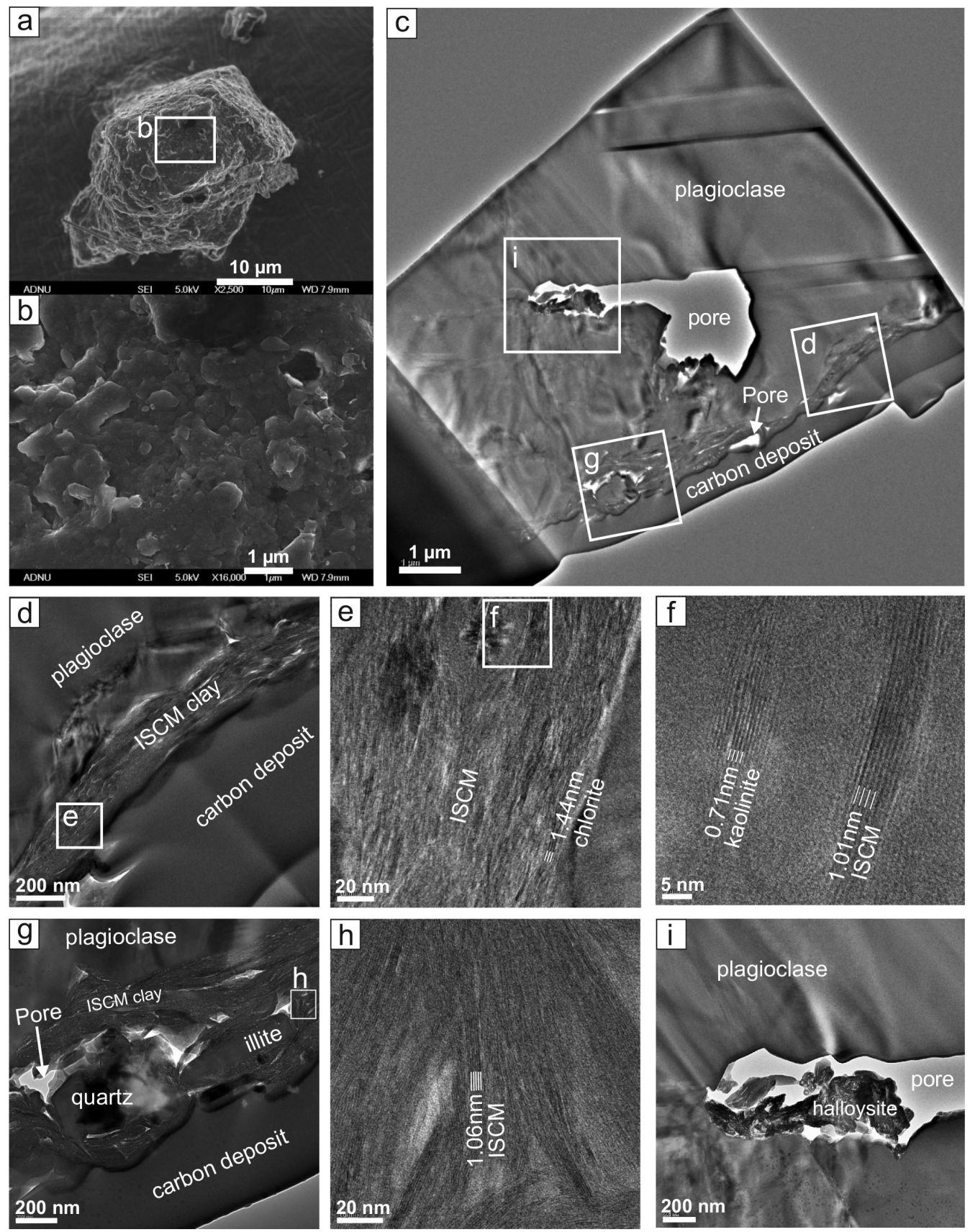

Figure 7. Plagioclase-rich dust particle from 2012 Asian dust. (a) SEM image of the dust particle. (b) SEM image of the particle surface magnified from the box in (a). (c) Overall TEM image of the FIB slice prepared from the particle in (a). (d) TEM image magnified from the box in (c). (e) TEM lattice fringe image of ISCMs and chlorite magnified from the box in (d). (f) TEM lattice fringe image of ISCM and kaolinite magnified from the box in (e). (g) TEM image magnified from the box in (c). (h) TEM lattice fringe image of ISCMs magnified from the box in (g). (i) TEM image of internal pore and halloysite magnified from the box in (c).

goethite (5.6\% area fraction) using EDXS and a $0.42 \mathrm{~nm}$ lattice fringe (Fig. 10e). EDXS analyses showed that biotite was depleted of interlayer $\mathrm{K}$, indicating $\mathrm{K}$ loss during weathering in the source soils. Goethite intergrowth in the weathered biotite is the result of oxidative weathering of biotite, where iron ions are released from the biotite lattice following oxidation (Jeong et al., 2006).

\subsubsection{Chlorite-rich particle}

The SEM images (Fig. 11a, b) show a chlorite-rich flaky particle covered with clay minerals. The slices prepared 

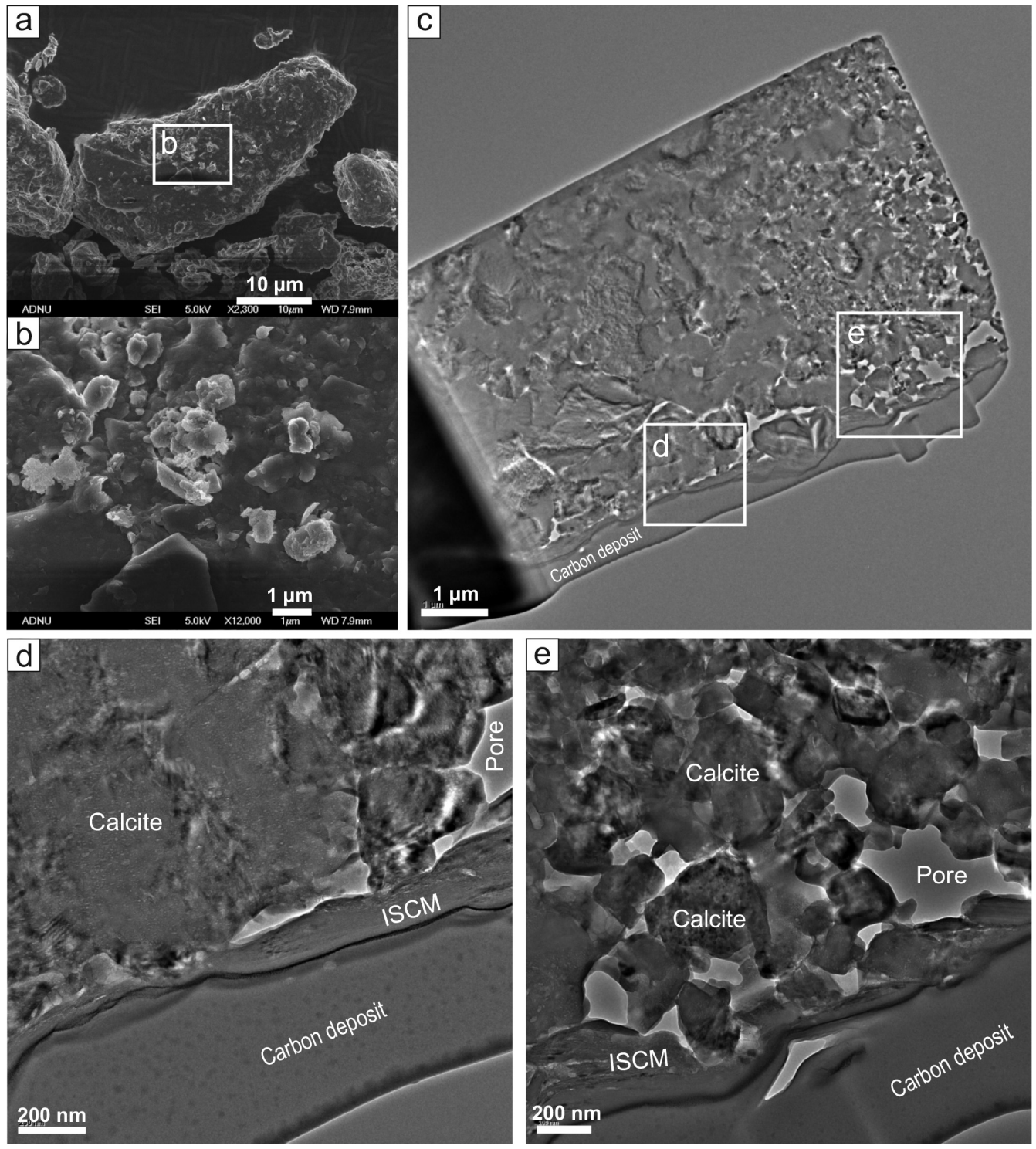

Figure 8. Calcite-rich dust particle from 2012 Asian dust. (a) SEM image of the dust particle. (b) SEM image of the particle surface magnified from the box in (a). (c) Overall TEM image of the FIB slice prepared from the particle in (a). (d, e) TEM images magnified from the box in (c).

perpendicular to the flake show that half of the flake consists of subparallel ISCM clay minerals (Fig. 11c). The other half is chlorite with long lenticular voids $(6.2 \%)$ that were propped by submicron crystals of goethite $(4.3 \%)$ (Fig. 11d) as identified by EDXS and a $0.41 \mathrm{~nm}$ lattice fringe (Fig. 11e). The EDXS analysis of chlorite showed a slight increase in silicon ( $\mathrm{Si}$ ) content compared with that of fresh chlorite, indicating oxidative weathering of chlorite followed by the formation of goethite crystals that consumed the iron released from chlorite lattices to maintain a charge balance. The growth of goethite crystals is responsible for the formation of lenticular voids.

\subsubsection{Iron-oxide-rich particle}

An iron-rich agglomerate particle is shown in Fig. 12a. An overall TEM image of a slice prepared from the particle shows the association of an irregular magnetite crystal and clusters of iron-oxide nanograins (Fig. 12b, c), which were identified as goethite by electron diffraction (inset in Fig. 12c). The micron pores and goethite were likely formed by the dissolution of magnetite during the weathering in the source soils. 

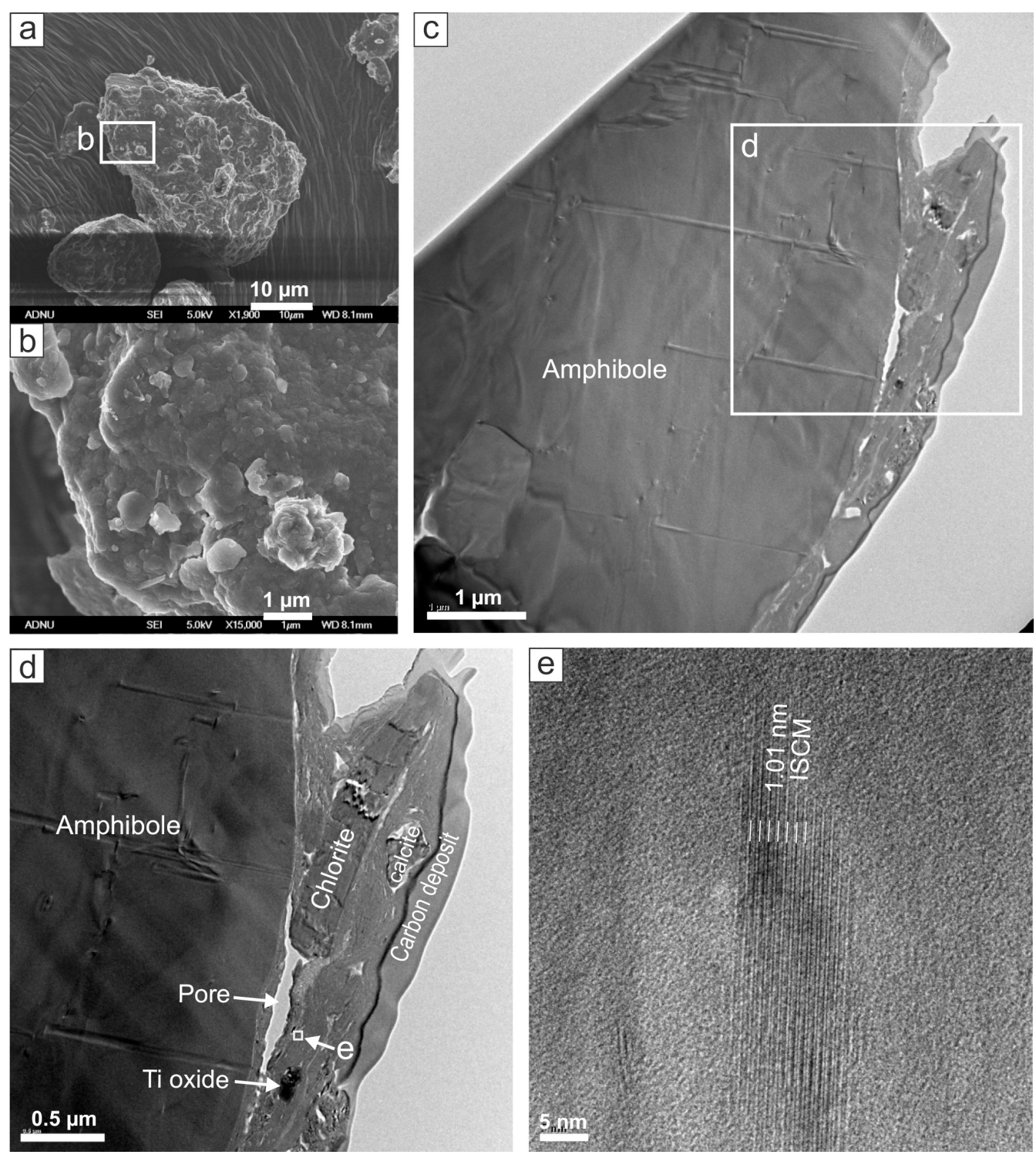

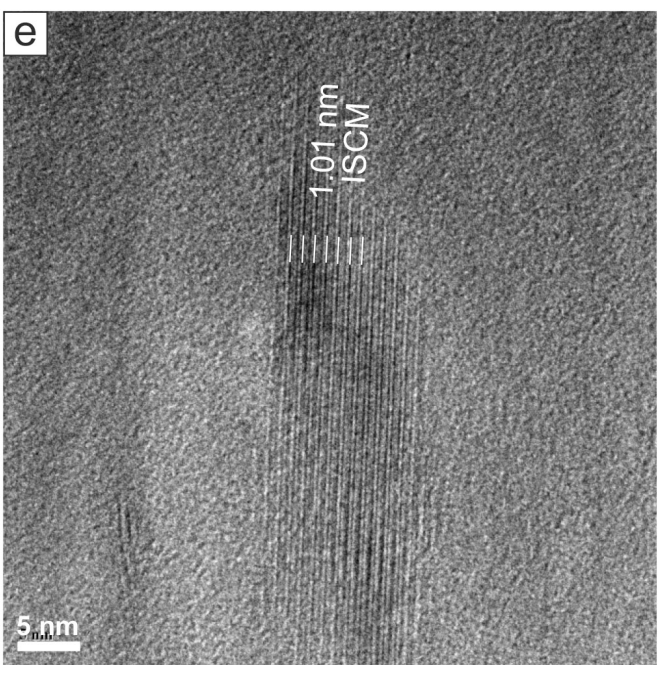

Figure 9. Amphibole-rich dust particle from 2012 Asian dust. (a) SEM image of the dust particle. (b) SEM image of the particle surface magnified from the box in (a). (c) Overall TEM image of the FIB slice prepared from the particle in (a). (d) TEM image magnified from the box in (c). (e) TEM lattice fringe image of ISCMs magnified from the box in (d).

\subsubsection{Polycrystalline/polymineralic rock fragment}

Minerals form compact, heterogeneous solids such as igneous, metamorphic, and sedimentary rocks in Earth's lithosphere. Some rocks consist of coarse mineral grains up to several centimeters in size, while other rocks consist of fine mineral grains, the sizes of which are as small as a few micrometers in size. The grain sizes of minerals in rocks commonly exceed the particle size of long-range transported dust. Therefore, original rock fragments composed of several interlocked mineral grains are relatively rare in longrange transported dust. The TEM image of a slice (Fig. 13b) prepared from the dust particle in Fig. 13a shows a rock- fragment particle composed of quartz, plagioclase (albite), biotite and chlorite grains of a few micrometer sizes identified by EDXS and electron diffractions (Fig. 13d-f). The mineral grains are not a loose agglomerate of fine soil grains, but rather compactly interlocked with each other to form heterogeneous solids. The rock fragments have some pores (Fig. 13b) and are coated with ISCM clay layers of $\sim 0.5 \mu \mathrm{m}$ thick scattered with goethite grains (Fig. 13c). The particle in Fig. 13c is a polycrystalline/polymineralic rock fragment, whereas the particle in Fig. 8 is an example of a polycrystalline/monomineralic rock fragment. 

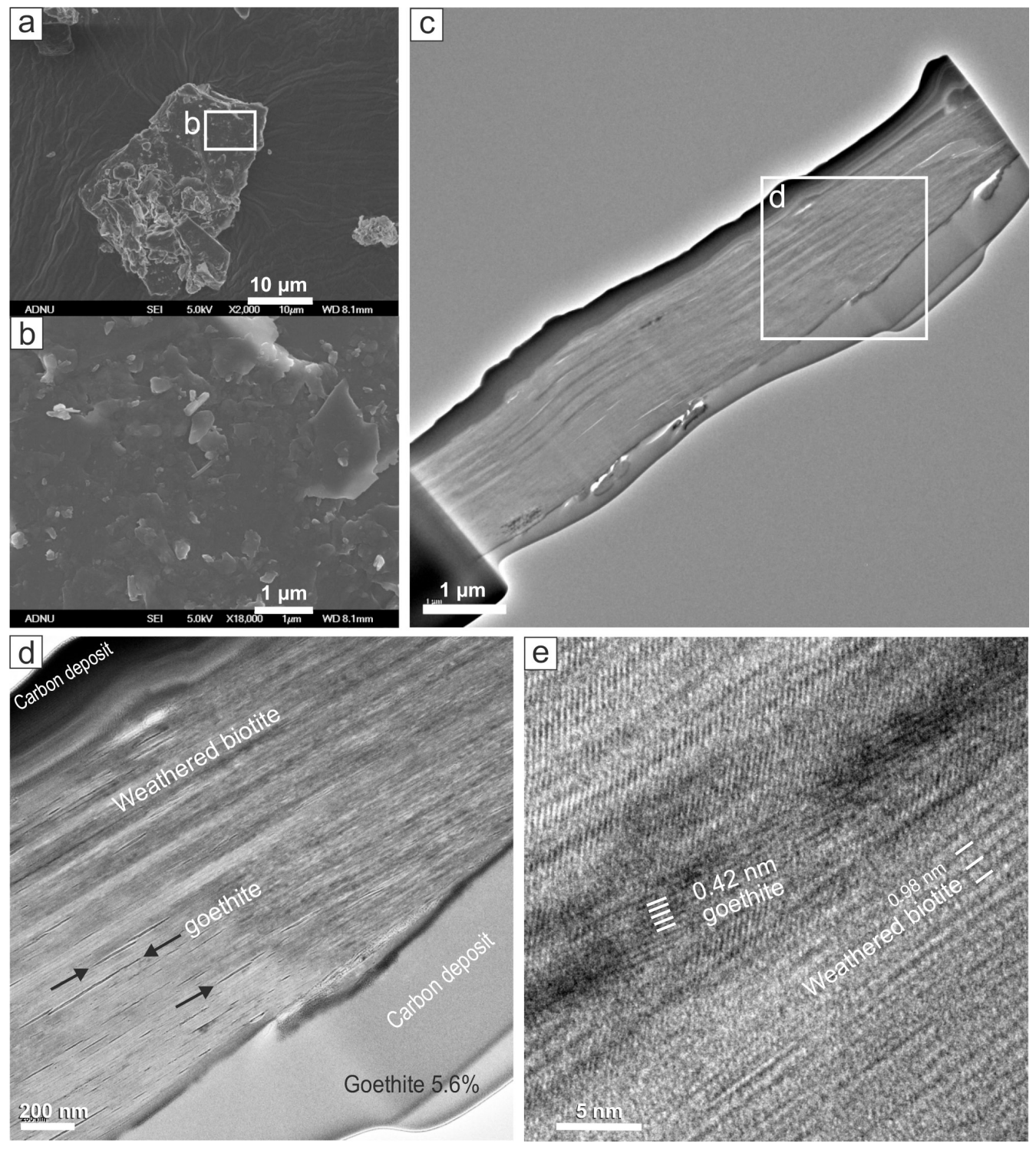

Figure 10. Biotite dust particle from 2012 Asian dust. (a) SEM image of the dust particle. (b) SEM image of the particle surface magnified from the box in (a). (c) Overall TEM image of the FIB slice prepared from the biotite particle in (a). (d) TEM image magnified from the box in (c). (e) TEM lattice fringe image of goethite in weathered biotite.

\subsection{Structural models}

To facilitate the optical modeling of mineral dust particles, the internal structures observed in Asian dust particles were grouped into idealized classes. We identified three major types of internal structure: Type I, coarse non-phyllosilicate minerals; Type II, nanocrystalline clay agglomerates; and Type III, coarse phyllosilicate plates.

Type-I dust particles have core grains of non-phyllosilicate minerals including quartz, plagioclase, calcite, K-feldspar, and amphibole in the order of abundance (Fig. 14). They exist as either monomineralic crystals (Figs. 5-9) or polymineralic rock fragments (Fig. 13). The monomineralic particles can also be further described as monocrystalline (Figs. 5, 6, 7,9 ) or polycrystalline (Fig. 8). Although some surfaces of the coarser core crystals are directly exposed, almost all the surfaces are covered with nanocrystalline ISCM clay coatings (ca. $0.2-1 \mu \mathrm{m}$ ). Therefore, there are six subtypes, as presented in Fig. 14. In Asian dust sources, all silt-size mineral grains have been observed to be coated with clay minerals according to an electron microscopic analysis of the silty soils as shown in Fig. 4 of Jeong (2008). The clay coatings are features acquired in the source soils via repeated wetting-drying and freezing-thawing cycles.

Type-II dust particles are clay agglomerates composed mainly of nanocrystalline clay minerals (Fig. 15). ISCM is 

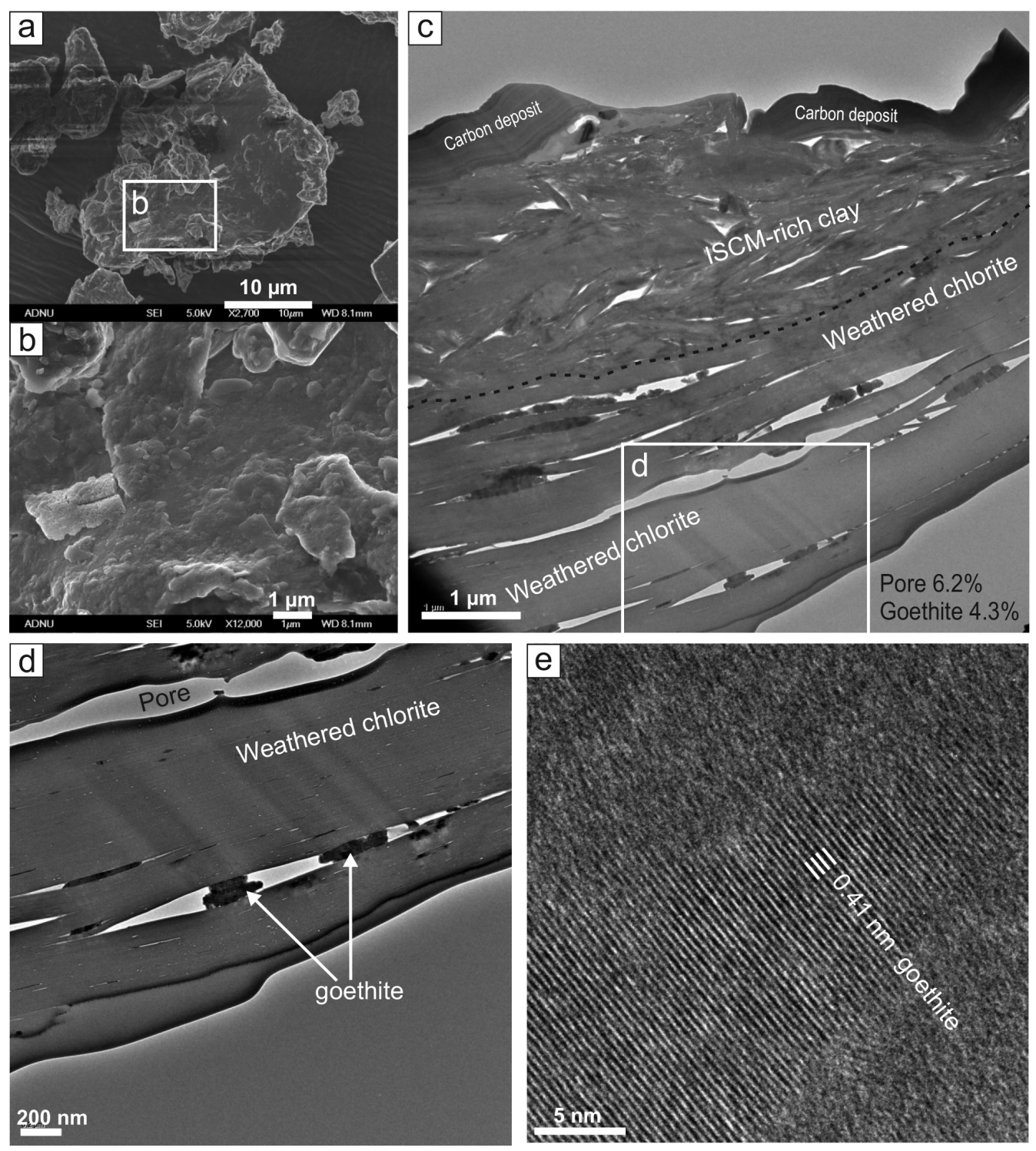

Figure 11. Chlorite-rich dust particle from 2012 Asian dust. (a) SEM image of the dust particle. (b) SEM image of the particle surface magnified from the box in (a). (c) Overall TEM image of the FIB slice prepared from the particle in (a). (d) TEM image magnified from the box in (c). (e) TEM lattice fringe image of goethite in the pore of weathered chlorite.

the most abundant mineral group in Asian dust (Jeong et al., 2014). As shown in the Figs. $2 d$ and $4 d$, the orientations of the nano-thin ISCM platelets are always subparallel in the nano scale. However, at larger scales, fabrics of clay agglomerates are diverse, ranging from complete lamination (Fig. 2c) to random (Fig. 4c). The clay agglomerates often have micron-scale pores of lenticular or irregular shapes (Figs. 2c, 3c, 4c). Agglomerates of pure clays are rare. Many clay-rich agglomerates include larger nonphyllosilicate grains (quartz, plagioclase, K-feldspar, and calcite) and coarser phyllosilicates (muscovite, biotite, and chlorite) (Figs. 2c, 3c, 4c). Therefore, clay agglomerates could be further classified into eight subtypes (Fig. 15).
Type-III particles are coarse phyllosilicates of muscovite, biotite, and/or chlorite (Fig. 16). The platy morphologies are regulated by the well-developed cleavages along the (001) basal planes. They are commonly coated with ISCM clays. Another feature of the internal structures is the occurrence of goethite (an iron oxyhydroxide) along the cleavages in the weathered biotite and chlorite, which is a feature acquired in the source soils. The lenticular voids occur in the weathered biotite and chlorite. Although we have not presented the data of muscovite, it is reportedly highly resistant to oxidative weathering due to the absence of iron. Thus, goethite microinclusions and lenticular voids are not expected in the internal structures of muscovite. Coarse phyllosilicates 

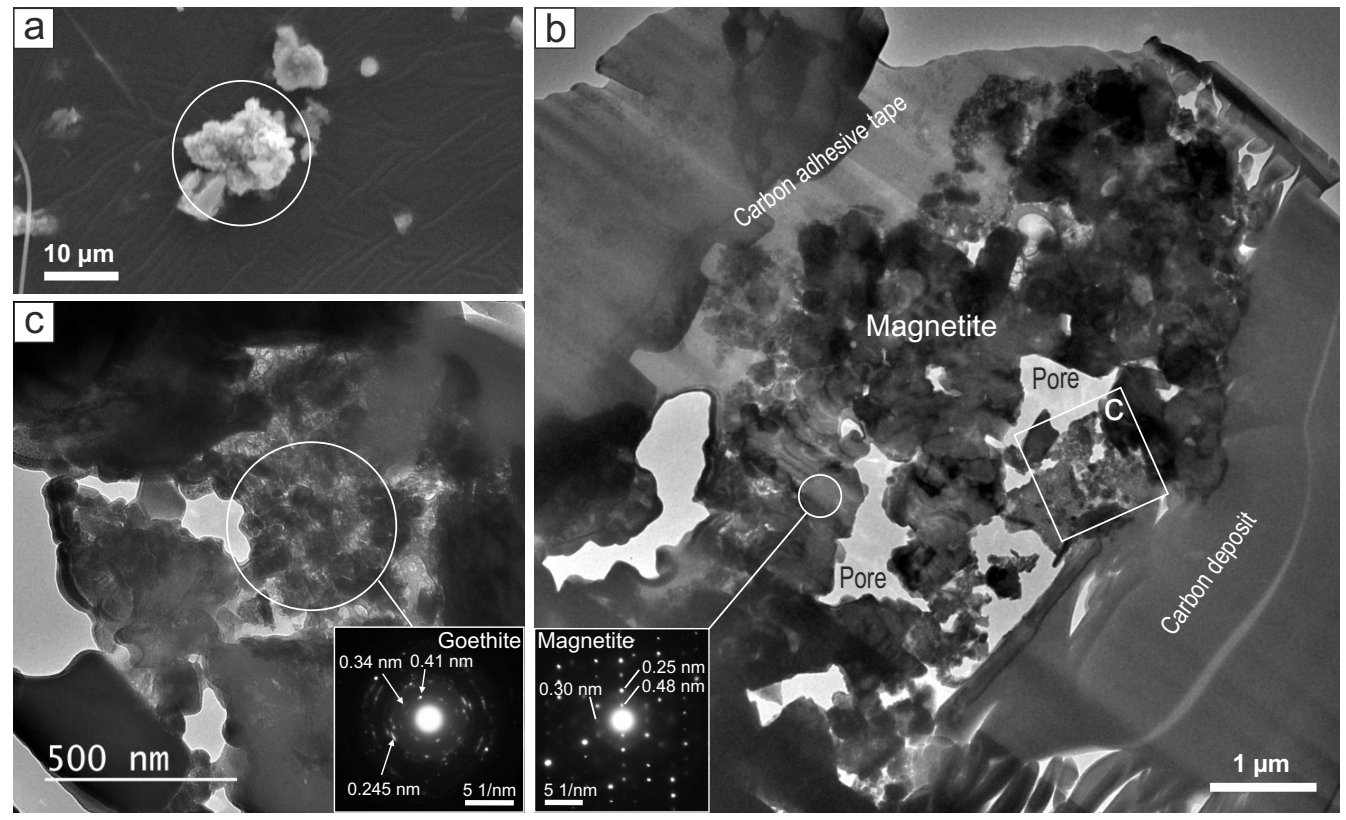

Figure 12. Iron-oxide-rich dust particle from 2012 Asian dust. (a) SEM image of the dust particle. (b) Overall TEM image of the FIB slice prepared from the particle in (a). (c) TEM image magnified from the box in (b). Electron diffraction patterns of the circled areas in (b) and (c) indicate goethite and magnetite, respectively.

could be further classified into four subtypes, as presented in Fig. 16.

The diameters of the particles milled by FIB in this study are generally large because most of the particles were selected from the coarse Asian dust observed in 2012. In future research to refine the internal structure models, much more attention should be paid to the long-range transport particles with modes around 2-4 $\mu \mathrm{m}$ in equivalent volume/mass diameter (Reid et al., 2003; Zender et al., 2003; McKendry et al., 2008). Nevertheless, we think that particles of several micrometers also have structural features similar to larger particles. In the arid desert soils, fine particles are formed by the repeated saltation, impact, and fragmentation of soil agglomerates by wind. As shown in Supplementary Fig. 2, fine particles derived from coarse agglomerate particles likely have internal structure types summarized in Figs. 14-16.

\subsection{Implications for the optical modeling of dust particles}

Individual dust particles are often composed of several mineral species. Their mineral grains and pores are arranged to form several types of internal structures, some of which could contribute significantly to the single-scattering properties of mineral dust. Our results imply that the presence of internal structures in natural dust particles is a rule rather than an exception. To quantify their effects on single-scattering properties, sophisticated simulations should be carried out. While this is clearly beyond the scope of the present study, we can nevertheless offer our first impressions and speculate on the possible impacts.

\subsubsection{Internal structures}

With regard to the geometrical characteristics of the internal structure, the most important factor is the size scale of the structure compared to the wavelength of radiation. This impacts not only the effectiveness of the structure in influencing single-scattering properties (sub-wavelength structures interact with radiation only weakly) but also impacts how it should be accounted for in modeling. If the structures are small compared to the wavelength, and sufficiently randomly located, effective medium approximations (e.g., Chylek et al., 2000) may be used, after which the particle can be treated as a homogeneous material with mean dielectric properties. However, as the example in Sect. 3.3.2 shows, the mixing of dielectrically very different materials can lead to strong effects, and to large errors if all the assumptions are not satisfied. For example, Kocifaj and Videen (2008) investigated errors arising from the use of effective medium approximations for particles that are mixtures of non-absorbing and absorbing constituents, and showed that all single-scattering properties were affected. The backscattering quantities relevant for lidar measurements were most affected. Some of the particles analyzed here also show mixtures of weakly and strongly absorbing constituents. In case of embedded crystals in an ISCM matrix (Fig. 4), the effective medium approximation may perform well, because of the small dielectric contrast between the constituents. Likewise, Kocifaj et al. (2008) 

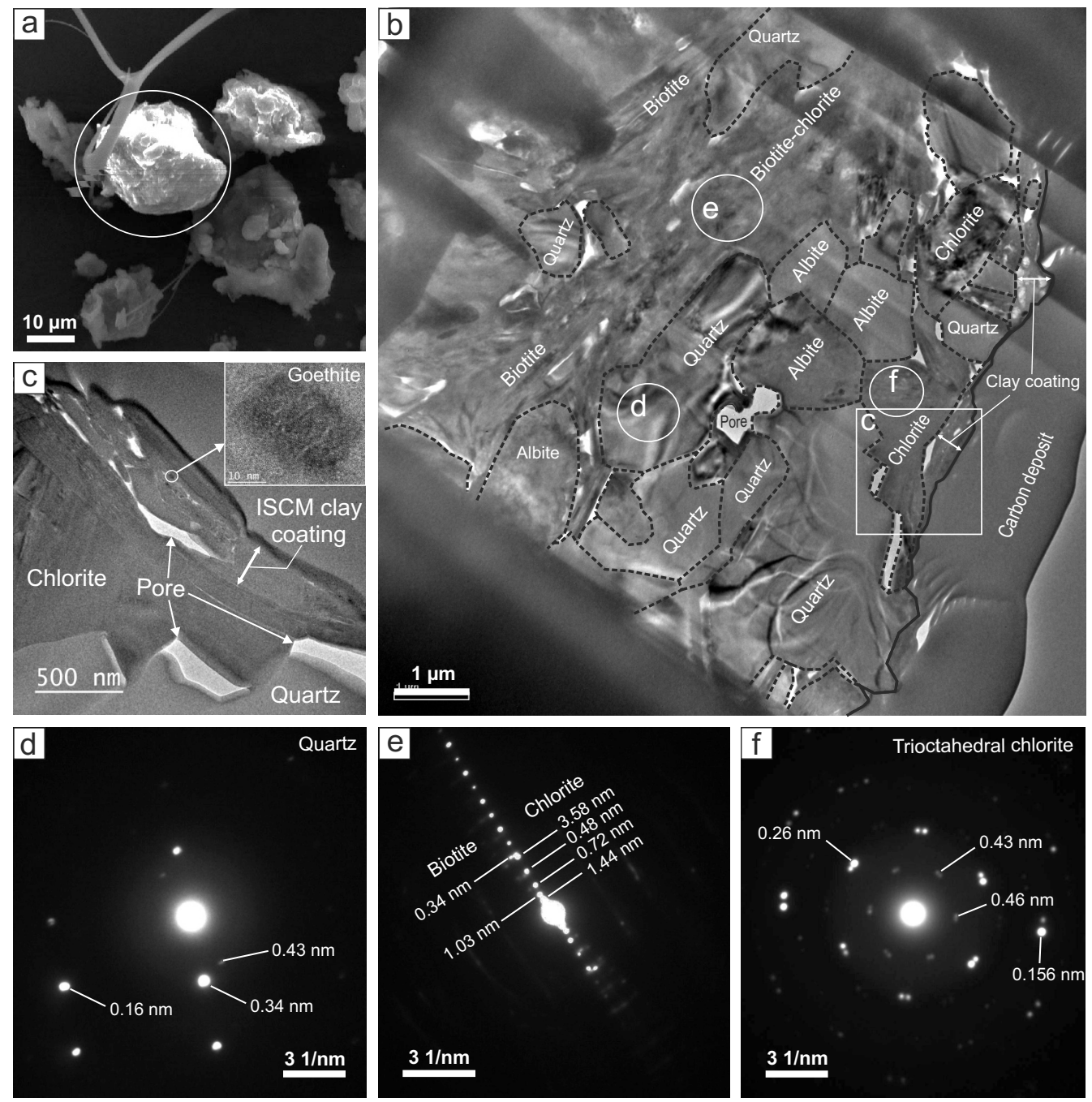

Figure 13. Rock fragment dust particle from 2012 Asian dust. (a) SEM image of the dust particle. (b) Overall TEM image of the FIB slice prepared from the rock fragment particle in (a). (c) TEM image magnified from the box in (b) showing the coatings of oriented nano-thin clay minerals with pore and goethite nanograins. (d, e, f) Electron diffraction patterns of the areas marked with circles.

reported up to 10 percent error in the asymmetry parameter for coated structures when treated with an effective medium approximation; coated structures are also present in our analyses, e.g., in Fig. 6. For particles with large pores inside, which present large structures with high dielectric contrasts, the effective medium approximations are likely to also fail. Strong effects on single-scattering properties due to internal pores are shown, e.g., by Nousiainen et al. (2011a). Therefore, the pores with fractional areas extending up to $16.3 \%$ are clearly significant and should be accounted for explicitly.

Another interesting aspect is that in many particles studied, the internal structure is far from random. Instead, we often see varying types of ordered structure. From the singlescattering point of view, the most important is whether these structures are also preferentially oriented. For example, the embedded constituent crystals may have preferred orienta- tion within the particle (e.g., Figs. 4c-e and 15). Such a structure may act to make the whole particle seemingly birefringent, even if composed of isotropic materials. Whether this is significant for the particles' single-scattering properties depends on the strength of this structural birefringence and the overall shape of the particle. From Nousiainen et al. (2009) we know that polarization quantities in particles are sensitive to birefringence; whereas, Dabrowska et al. (2012) reports that the effect increases with increasing particle aspect ratio. For example, the preferred orientation of the platelets in clay layers (e.g., Figs. 14 and 16) may give rise to structural birefringence, especially if the particle is elongated, because then there will be more platelets oriented parallel to the longer particle axis than perpendicular to it. Likewise, ordered layered structures, such as those seen in Figs. 10c, d, 11c, and d, may give rise to structural birefringence. Again, this depends 
Quartz, plagioclase, K-feldspar, and calcite crystals

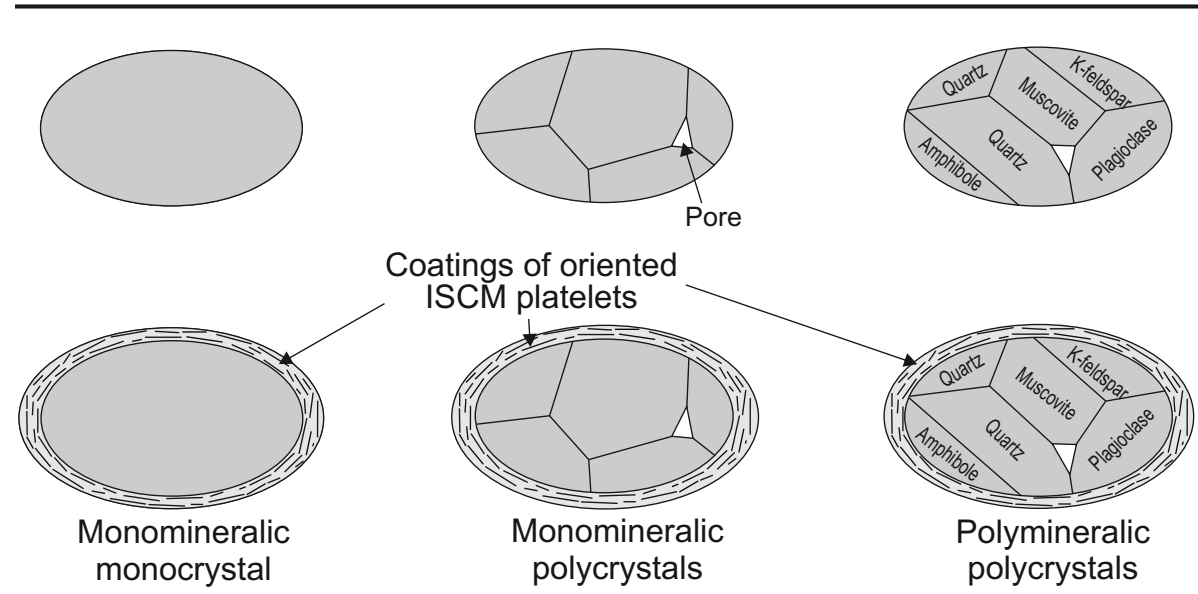

Figure 14. Type-I structural models for single and polycrystals of quartz, plagioclase, K-feldspar, and calcite with clear or clay-coated surfaces. Clay minerals are dominated by ISCMs.

on how preferential the orientations of such structures are in the particle.

\subsubsection{Mineralogy}

Mineral dust particles can be composed of numerous grains of several mineral species with different refractive indices and sizes. The single-scattering properties of the particles will depend on the internal mixing state, size, and distribution of the constituent grains. For the effect to be substantial, however, the refractive indices of the different grains must vary considerably. Iron oxides are considered to be the most important minerals in this respect, because they are relatively common and the real and imaginary parts of their refractive indices are considerably higher than those for most other mineral species typically encountered in atmospheric dust. There are many reports that even small amounts of iron oxides can be significant for the single-scattering properties of dust. For example, Sokolik and Toon (1999) found that even $1 \%$ hematite mixed with kaolinite was sufficient to decrease the dust particles' modeled single-scattering albedo by $\sim 10 \%$ when assuming an internal mixture treated with effective medium approximation instead of an external mixture. Similarly, when Balkanski et al. (2007) attempted to constrain dust refractive indices by varying the hematite content in the internal mixture to fit AERONET data, they found that a subtle variation in hematite contents and their mixing state were critical in explaining the observed refractive indices by AERONET, and in evaluating the global net radiative effect. Lindqvist et al. (2014) also found that a few volume percent of hematite was sufficient to impact the simulated single-scattering properties of dust particles.

Confirmations of the specific properties possessed by iron oxides are rare, despite their great importance and many related assumptions. The identification of iron oxide miner- als (hematite or goethite) has not been attempted other than by the diffuse reflectance spectroscopic analysis of Lafon et al. (2006). Goethite has different wavelength-dependent refractive indices from hematite (Bedidi and Cervelle, 1993). In addition, the actual impact of iron oxides depends on the grain size and distribution of iron oxides within a particle. For example, widely distributed small iron oxide grains will lead to stronger absorption than a few larger grains of identical total mass.

The results of our study indicate that iron oxides are evenly distributed in the clay agglomerates, normally as submicronsize grains. Lafon et al. (2006), using diffuse reflectance spectroscopy, also showed that goethite was a major iron oxide in dust samples collected near the desert margin of China $\left(38^{\circ} 17^{\prime} \mathrm{N}, 109^{\circ} 43^{\prime} \mathrm{E}\right)$. The estimated areal fractions of goethite range from 0.6 to $5.6 \%$ for those particles where it was present. The even distribution of submicron goethite particles suggests potentially considerable impacts on the particles' single-scattering properties.

Biotite, chlorite, and their weathered equivalents have also been found above trace quantities in Asian dust (Jeong et al., 2014). Their dark color and iron-rich chemical compositions suggest clearly higher imaginary parts of the complex refractive indices than those of colorless minerals such as quartz, feldspars, muscovite, calcite, or ISCMs. However, their complex refractive indices have not been experimentally measured over a wide range of wavelengths (Mooney and Knacke, 1985). In addition, the grain sizes and spatial distribution of titanium oxides (possibly rutile and anatase) within dust particles are similar to those of iron oxides. Their high refractive indices (Cardona and Harbeke, 1965) may also significantly contribute to the single-scattering properties of dust, which deserve further investigation. 


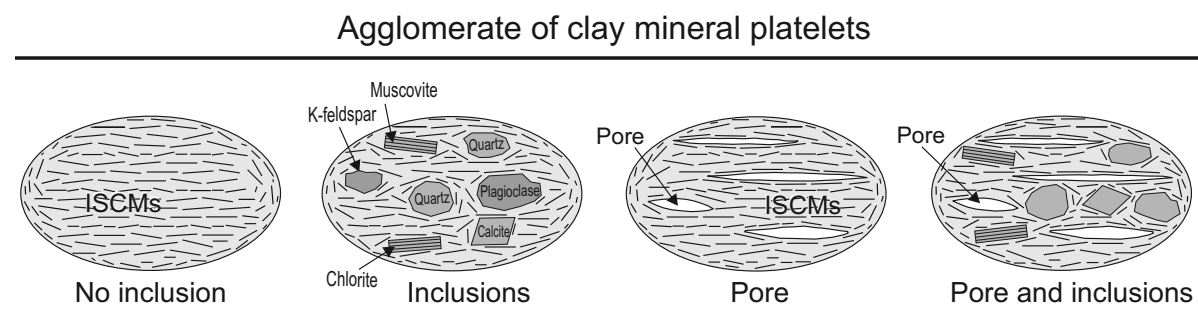

Preferred orientation of nano-thin ISCM platelets
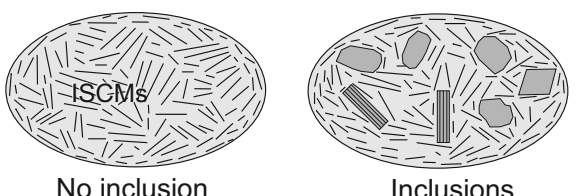

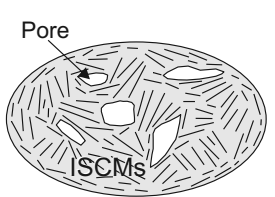

Pore and no inclusion

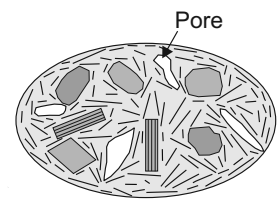

Pore and inclusions

Random orientation of nano-thin ISCM platelets

Figure 15. Type-II structural models for ISCM-clay-rich particles with preferentially or randomly oriented nano-thin clay platelets, and with pores and inclusions of nonphyllosilicates, micas (muscovite and biotite), and chlorite.

Large plates of micas (muscovite and biotite) and chlorite

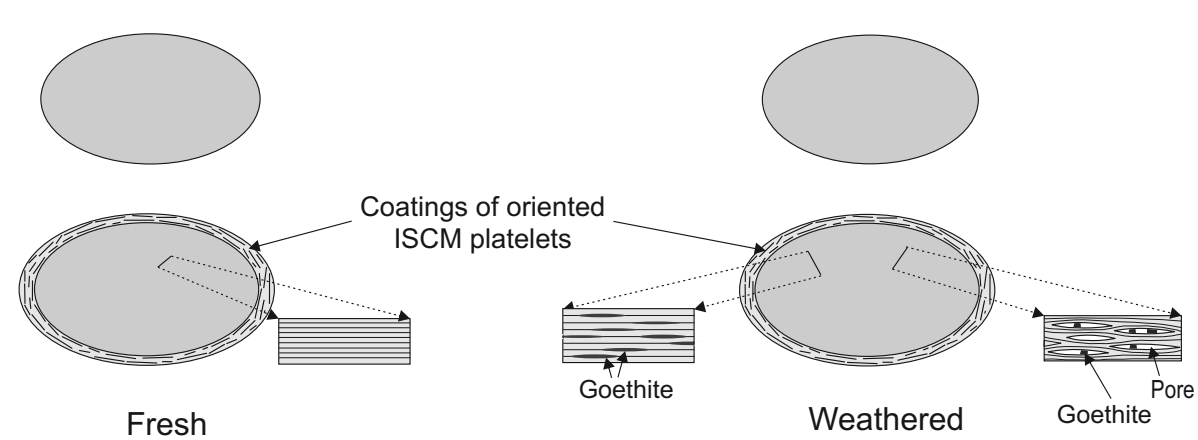

Figure 16. Type-III structural models for plates of micas (muscovite and biotite) and chlorite, which are either fresh or weathered. Weathered biotite and chlorite contain goethite crystals and lenticular pores.

\subsection{Implications for climate and remote sensing}

The radiative impacts of mineral dust are ultimately derived from their single-scattering properties averaged over all sizes and shapes present. In principle, it is possible that the internal structures observed cause systematic effects on singlescattering dust properties that persist through the averaging and can therefore be important in radiation-related applications. The most important of such applications in atmospheric sciences are climate modeling and remote sensing.

For the internal structure of particles to substantially impact climate through radiation, two prerequisites must be satisfied: (1) the dust single-scattering properties need to be affected sufficiently, and (2) the dust optical depth needs to be sufficiently large. Räisänen et al. (2013) recently investigated the impact of dust-particle non-sphericity on climate and found the effect to be negligible on a global scale, but possibly important locally. We can expect the same to hold for the impact of internal structure. There exists the potential for large and fairly systematic impacts to singlescattering properties similar to those due to particle nonsphericity. However, the globally averaged dust optical depth is too small to allow for significant global impacts. Local and regional effects are possible, but depend on the impact on the single-scattering properties, which are yet to be quantified. We also note that atmospheric dust loadings during the last glacial maximum were an order-of-magnitude larger than today, thereby inducing much stronger global effects (Harrison et al., 2001).

In terms of remote sensing, the potential for important implications is much greater. Remote observations are usually directional and therefore dependent on the differential single-scattering properties that can be quite sensitive to the physical properties of particles. Again, the impacts depend on how the single-scattering properties are affected, which is yet to be quantified; however, it is safe to assume that 
different types of remote sensing measurements will be affected differently. For example, polarization quantities are more likely to be affected than the intensity (Nousiainen et al., 2009; Nousiainen et al., 2012). Further, we speculate that lidar observations, looking at the exact backscattering angle, may be particularly sensitive to internal structure. We also emphasize that the impact may extend to atmospheric remote sensing beyond aerosol measurements, because the radiative impact of aerosols often needs to be accounted for and corrected even when measuring other atmospheric constituents, or when measuring through the atmosphere.

Even though the present investigation considered a few dust particles, the major types of internal structure obtained by TEM analysis can be integrated with statistical data obtained by SEM single particle analysis as done by Jeong et al. (2014) to estimate the proportions of the structural types, and followed by the simulation of the optical properties of bulk dust. However, evidently there are long steps toward the optical simulation of bulk dust. Optical property of each structural type can be modeled first, and then we may progress to model bulk dust considering the proportions of the structural types.

\section{Summary and conclusion}

Optical models for the interaction between dust and electromagnetic radiation are important in the evaluation of net radiative effects, and in the processing of remote sensing data. All microphysical properties, including size distributions, particle morphology, and composition should be known and accounted for to allow for realistic optical single-scattering treatment. Of the many uncertainties in bulk microphysical properties, the most uncertain are the properties of individual particles that ultimately govern the radiative effects. Yet, strictly speaking, true bulk optical properties of mineral dust aerosol cannot be obtained without this information, because the single-scattering properties of each particle depend on their size and shape in a composition-dependent way. The use of the same bulk composition for each particle in the single-scattering computations yields correct results only if each particle truly has the same composition, which is not the case. For any heterogeneous particle ensembles, one should compute particle-specific single-scattering properties which, for the additive quantities, can then be averaged. For most accurate radiative treatments, single-particle microphysical properties are needed. In the past, optical models have been based on many assumptions and simplifications of the mineralogical and structural properties of individual particles such as species, size, mixing state, and arrangement of constituent minerals. This study directly explored the interior of individual Asian dust particles, revealing many novel microphysical details of the constituent mineralogy and internal structures.

Individual dust particles are composed of several mineral species of varying grain sizes. Iron oxides, known as the most important minerals with large real and imaginary parts of the refractive index, were scattered as submicronsized grains throughout clay agglomerates. Goethite was the dominant iron oxide. In addition, we suggest that submicron titanium oxides, chlorite, and biotite are worth considering as optically significant minerals. The internal structures of individual dust particles were formed by the patterned arrangement of nano-to-micron-sized mineral grains and pores. Internal structures could be grouped into three major types: coarse cores of quartz, feldspars, calcite, and amphibole with oriented clay coatings; clay agglomerates of nano-thin clay platelets; and coarse platy phyllosilicates of muscovite, biotite, and chlorite. Nano-thin platelets of clay minerals were dominated by the illite-smectite series clay minerals with subordinate kaolinite and clay-sized chlorite.

The observed internal structures and mineralogy are potentially important factors for the single-scattering properties of Asian dust particles. For example, the contrasting dielectric properties of pores and constituent minerals may greatly impact light scattering by dust particles, while structural birefringence by the preferred alignment of nano-thin claymineral platelets or micron-size phyllosilicate plates may also produce significant effects. Directional remote sensing, for example lidar examining the exact backscattering angle, is strongly dependent on differential single-scattering properties, and may be particularly sensitive to a particles' internal structure. In addition, local and regional net radiative effects due to dust may depend on the structural and compositional properties of dust particles. The microphysical parameters of individual dust particles considered in this study can be explicitly accounted for in single-scattering modeling if sophisticated methods, such as a discrete-dipole approximation by Draine and Flatau (1994), are used. Such modeling studies can illustrate the means by, and degree to, which microphysical parameters influence dust particle single-scattering properties, and will allow for further investigation of the dust radiative effect and remote-sensing implications. In the future, we plan to both carry out such simulations and to measure the internal structures for more dust particles and from different sources.

\section{The Supplement related to this article is available online at doi:10.5194/acp-14-7233-2014-supplement.}

Acknowledgements. We are grateful to the anonymous referees for their critical comments and suggestions. This study was funded by the National Research Foundation of Korea grant NRF-20110028597, and in part, by the Academy of Finland (grant 255718) and the Finnish Funding Agency for Technology and Innovation (Tekes; grant 3155/31/2009).

Edited by: A. Laskin 


\section{References}

Adler, G., Koop, T., Haspel, C., Taraniuk, I., Moise, T., Koren, I., Heiblum, R. H., and Rudich, Y.: Formation of highly porous aerosol particles by atmospheric freeze-drying in ice clouds, $\mathrm{P}$. Natl. Acad. Sci. USA, 110, 20414-20419, 2013.

Anderson, J. R., Buseck, P. R., Patterson, T. L., and Arimoto, R.: Characterization of the Bermuda tropospheric aerosol by combined individual-particle and bulk-aerosol analysis, Atmos. Environ., 30, 319-338, 1996.

Balkanski, Y., Schulz, M., Claquin, T., and Guibert, S.: Reevaluation of Mineral aerosol radiative forcings suggests a better agreement with satellite and AERONET data, Atmos. Chem. Phys., 7, 81-95, doi:10.5194/acp-7-81-2007, 2007.

Bedidi, A. and Cervelle, B.: Light scattering by spherical particles with hematite and goethitelike optical properties: effect of water impregnation, J. Geophy. Res., 98, 11941-11952, 1993.

Cardona, M. and Harbeke, G.: Optical properties and band structure of wurtzite-type crystals and rutile, Phys. Rev., 137, A1467A1476, 1965.

Chen, G., Ziemba, L. D., Chu, D. A., Thornhill, K. L., Schuster, G. L., Winstead, E. L., Diskin, G. S., Ferrare, R. A., Burton, S. P., Ismail, S., Kooi, S. A., Omar, A. H., Slusher, D. L., Kleb, M. M., Reid, J. S., Twohy, C. H., Zhang, H., and Anderson, B. E.: Observations of Saharan dust microphysical and optical properties from the Eastern Atlantic during NAMMA airborne field campaign, Atmos. Chem. Phys., 11, 723-740, doi:10.5194/acp11-723-2011, 2011.

Chou, C., Formenti, P., Maille, M., Ausset, P., Helas, G., Harrison, M., and Osborne, S.: Size distribution, shape, and composition of mineral dust aerosols collected during the African Monsoon Multidisciplinary Analysis Special Observation Period 0: Dust and Biomass-Burning Experiment field campaign in Niger, January 2006, J. Geophy. Res., 113, D00C10, doi:10.1029/2008JD009897, 2008.

Chudnovsky, A., Ben-Dor, E., Kostinski, A. B., and Koren, I.: Mineral content analysis of atmospheric dust using hyperspectral information from space, Geophys. Res. Lett., 36, L15811, doi:10.1029/2009GL037922, 2009.

Chylek, P., Videen, G., Geldart, D. J. W., Dobbie, J. S., and Tso, H. C. W.: Effective medium approximations for heterogeneous particles, in: Light Scattering by Nonspherical Particles, edited by: Mishchenko, M. I., Hovenier, J. W., Travis, L. D., Academic Press, printed in the USA, 273-308, 2000.

Conny, J. M.: Internal composition of atmospheric dust particles from focused ion-beam scanning electeron microscopy, Environ. Sci. Technol., 47, 8575-8581, 2013.

Dabrowska, D. D., Muñoz, O., Moreno, F., Nousiainen, T., and Zubko, E.: Effect of the orientation of the optic axis on simulated scattering matrix elements of small birefringent particles, Opt. Lett., 37, 3252-3254, 2012.

Derimian, Y., Karnieli, A., Kaufman, Y. J., Andreae, M. O., Andreae, T. W., Dubovik, O., Maenhaut, W., and Koren, I.: The role of iron and black carbon in aerosol light absorption, Atmos. Chem. Phys., 8, 3623-3637, doi:10.5194/acp-8-3623-2008, 2008.

Díaz-Hernández, J. L. and Párraga, J.: The nature and tropospheric formation of iberulite: Pinkish mineral microspherulites, Geochim. Cosmochim. Ac., 72, 3883-3906, 2008.
Draine, B. T. and Flatau, P. J.: Discrete-dipole approximation for scattering calculations, J. Opt. Soc. Am. A, 11, 1491-1499, 1994.

Dubovik, O. and King, M. D.: A flexible inversion algorithm for retrieval of aerosol optical properties from sun and sky radiance measurements, J. Geophys. Res., 105, 20673-20696, 2000.

Dubovik, O., Sinyuk, A., Lapyonok, T., Holben, B. N., Mishchenko, M., Yang, P., Eck, T. F., Volten, H., Munoz, O., Veihelmann, B., van der Zande, W. J., Leon, J. F., Sorokin, M., and Slutsker, I.: Application of spheroid models to account for aerosol particle nonsphericity in remote sensing of desert dust, J. Geophys. Res.Atmos., 111, D11208, doi:10.1029/2005JD006619, 2006.

Falkovich, A. H., Ganor, E., Levin, Z., Formenti, P., and Rudich, Y.: Chemical and mineralogical analysis of individual mineral dust particles, J. Geophys. Res.-Atmos., 106, 18029-18036, 2001.

Formenti, P., Schütz, L., Balkanski, Y., Desboeufs, K., Ebert, M., Kandler, K., Petzold, A., Scheuvens, D., Weinbruch, S., and Zhang, D.: Recent progress in understanding physical and chemical properties of African and Asian mineral dust, Atmos. Chem. Phys., 11, 8231-8256, doi:10.5194/acp-11-8231-2011, 2011.

Forster, P., Ramaswamy, V., Artaxo, P., Berntsen, T., Betts, R., Fahey, D. W., Haywood, J., Lean, J., Lowe, D. C., Myhre, G., Nganga, J., Prinn, R., Raga, G., Schulz, M., and Van Dorland, R.: Changes in Atmospheric Constituents and in Radiative Forcing, in: Climate Change 2007: The Physical Science Basis, Contribution of Working Group I to the Fourth Assessment Report of the Intergovernmental Panel on Climate Change, edited by Solomon, S., Qin, D., Manning, M., Chen, Z., Marquis, M., Averyt, K. B., Tignor, M., and Miller, H. L., Cambridge University Press, printed in United Kingdom, 2007.

Gao, Y., Anderson, J. R., and Hua, X.: Dust characteristics over the North Pacific observed through shipboard measurements during the ACE-Asia experiment, Atmos. Environ., 41, 7907-7922, 2007.

Harrison, S. P., Kohfeld, K. E., Roelandt, C., and Claquin, T.: The role of dust in climate changes today, at the last glacial maximum and in the future, Earth-Sci. Rev., 54, 43-80, 2001.

Haywood, J. M., Francis, P, Osborne, S. R., Glew, M., Loeb, N., Highwood, E., Tanré, D., Myhre, G., Formenti, P., and Hirst, E.: Radiative properties and direct radiative effect of Saharan dust measured by the C-130 aircraft during SHADE. 1. Solar spectrum, J. Geophys. Res. 108, 8577, doi:10.1029/2002JD002687, 2003.

Haywood, J. M., Allan, R. P., Culverwell, I., Slingo, T., Milton, S., Edwards, J., and Clerbaux, N.: Can desert dust explain the outgoing longwave radiation anomaly over the Sahara during July 2003?, J. Geophys. Res., 110, D05105, doi:10.1029/2004JD005232, 2005.

Haywood, J. M., Johnson, B. T., Osborne, S. R., Baran, A. J., Brooks, M., Milton, S. F., Mulcahy, J., Walters, D., Allan, R. P., Klaver, A., Formenti, P., Brindley, H. E., Christopher, S., and Gupta, P.: Motivation, rationale and key results from the GERBILS Saharan dust measurement campaign, Q. J. Roy. Meteor. Soc., 137, 1106-1116, 2011.

Ishitani, T., Umemura, K., Ohnishi, T., Yaguchi, T., and Kamino, T.: Improvements in performance of focused ion beam crosssectioning: aspects of ion-sample interaction, J. Electron Microsc., 53, 443-449, 2004. 
Jeong, G. Y.: Bulk and single-particle mineralogy of Asian dust and a comparison with its source soils, J. Geophys. Res.-Atmos., 113, D02208, doi:10.1029/2007JD008606, 2008.

Jeong, G. Y. and Kim, S. J.: Boxwork fabric of halloysite-rich kaolin formed by weathering of anorthosite in Sancheong area, Korea, Clay. Clay Miner., 41, 56-65, 1993.

Jeong, G. Y., Cheong, C.-S., and Kim, J.: Rb-Sr and K-Ar systems of biotite in surface environments regulated by weathering processes with implications for isotopic dating and hydrological cycles of Sr isotopes, Geochim. Cosmochim. Ac., 70, 4734-4739, 2006.

Jeong, G. Y., Kim, J. Y., Seo, J., Kim, G. M., Jin, H. C., and Chun, Y.: Long-range transport of giant particles in Asian dust identified by physical, mineralogical, and meteorological analysis, Atmos. Chem. Phys., 14, 505-521, doi:10.5194/acp-14-505-2014, 2014.

Kato, N. I.: Reducing focused ion beam damage to transmission electron microscopy samples, J. Electron Microsc., 53, 451-458, 2004.

Kandler, K., Benker, N., Bundke, U., Cuevas, E., Ebert, M., Knippertz, P., Rodríguez, S., Schütz, L., and Weinbruch, S.: Chemical composition and complex refractive index of Saharan Mineral Dust at Izaña, Tenerife (Spain) derived by electron microscopy, Atmos. Environ., 41, 8058-8074, 2007.

Kim, S.-W., Yoon, S.-C., and Kim, J.: Columnar Asian dust particle properties observed by sun/sky radiometers from 2000 to 2006 in Korea, Atmos. Environ., 42, 492-504, 2008.

Kocifaj, M. and Videen, G.: Optical behavior of composite carbonaceous aerosols: DDA and EMT approaches. J. Quant. Spectrosc. Ra., 109, 1404-1416, doi:10.1016/j.jqsrt.2007.11.007, 2008.

Kocifaj, M., Kundracik, F., and Videen, G.: Optical properties of single mixed-phase aerosol particles, J. Quant. Spectrosc. Ra., 109, 2108-2123, doi:10.1016/j.jqsrt.2008.03.006, 2008.

Koven, C. D. and Fung, I.: Inferring dust composition from wavelength-dependent absorption in Aerosol Robotic Network (AERONET) data, J. Geophys. Res., 111, D14205, doi:10.1029/2005JD006678, 2006.

Kulkarni, P., Baron, P. A., and Willeke, K.: Aerosol Measurement Principles, Techniques, and Applications, Wiley, printed in USA, 2011.

Lafon, S., Sokolik, I. N., Rajot, J. L., Caquineau, S., and Gaudichet, A.: Characterization of iron oxides in mineral dust aerosols: Implications for light absorption, J. Geophys. Res., 111, D21207, doi:10.1029/2005JD007016, 2006.

Lenoble, J., Remer, L. A., and Tanré, D.: Introduction, in: Aerosol remote sensing, edited by: Lenoble, J., Remer, L. A., and Tanré, D., Springer, printed in USA, 1-11, 2013.

Lindqvist, H., Jokinen, O., Kandler, K., Scheuvens, D., and Nousiainen, T.: Single scattering by realistic, inhomogeneous mineral dust particles with stereogrammetric shapes, Atmos. Chem. Phys., 14, 143-157, doi:10.5194/acp-14-143-2014, 2014.

Mayer, J., Giannuzzi, L. A., Kamino, T., and Michael, J.: TEM sample preparation and FIB-induced damage, MRS Bull., 32, 400407, 2007.

McKendry, I. G., Macdonald, A. M., Leaitch, W. R., van Donkelaar, A., Zhang, Q., Duck, T., and Martin, R. V.: Trans-Pacific dust events observed at Whistler, British Columbia during INTEXB, Atmos. Chem. Phys., 8, 6297-6307, doi:10.5194/acp-8-62972008, 2008.
Mooney, T. and Knacke, R. F.: Optical constants of chlorite and serpentine between 2.5 and $50 \mu \mathrm{m}$, Icarus, 64, 493-502, 1985.

Moosmüller, H., Engelbrecht, J. P., Skiba, M., Frey, G., Chakrabarty, R. K., and Arnott, W. P.: Single scattering albedo of fine mineral dust aerosols controlled by iron concentration, J. Geophs. Res., 117, D11210, doi:10.1029/2011JD016909, 2012.

Muinonen, K., Nousiainen, T., Lindqvist, H., Muñoz, O., and Videen, G.: Light scattering by Gaussian particles with internal inclusions and roughened surfaces using ray optics, J. Quant. Spectrosc. Radiat. Transfer, 110, 1628-1639, doi:10.1016/j.jqsrt.2009.03.012, 2009.

National Meteorological Satellite Center: http://nmsc.kma.go.kr/ html/homepage/en/main.do (last access: 10 May 2014), 2014.

Nousiainen, T., Muinonen, K., and Räisänen, P.: Scattering of light by large Saharan dust particles in a modified ray optics approximation, J. Geophys. Res., 108, 4025, doi:10.1029/2001JD001277, 2003.

Nousiainen, T.: Optical modeling of mineral dust particles: A review. J. Quant. Spectrosc. Ra., 110, 1261-1279, doi:10.1016/j.jqsrt.2009.03.002, 2009.

Nousiainen, T. and Kandler, K.: Light scattering by atmospheric mineral dust particles. Light Scattering Reviews, 9, in press, 2014.

Nousiainen, T., Zubko, E., Niemi, J. V., Kupiainen, K., Lehtinen, M., Muinonen, K., and Videen, G.: Single-scattering modeling of thin, birefringent mineral-dust flakes using the discrete-dipole approximation, J. Geophys. Res., 114, D07207, doi:10.1029/2008JD011564, 2009.

Nousiainen, T., Kahnert, M., and Lindqvist, H.: Can particle shape information be retrieved from light-scattering observations using spheroidal model particles?, J. Quant. Spectrosc. Ra., 112, 2213 2225, 2011a.

Nousiainen, T., Lindqvist, H., McFarquhar, G., and Um J.: Small irregular ice crystals in tropical cirrus, J. Atmos. Sci., 68, 2614 2627, 2011b.

Nousiainen, T., Zubko, E., Lindqvist, H., Kahnert, M., and Tyynelä, J.: Comparison of scattering by different nonspherical, wavelength-scale particles. J. Quant. Spectrosc. Ra., 113, 23912405, doi:10.1016/j.jqsrt.2012.03.032, 2012.

Okada, K., Naruse, H., Tanaka, T., Nemoto, O., Iwasaka, Y., Wu, P.M., Ono, A., Duce, R. A., Uematsu, M., and Merrill, J. T.: X-ray spectrometry of individual Asian dust-strom particles over the Japanese islands and the north Pacific Ocean, Atmos. Environ. A-Gen., 24, 1369-1378, 1990.

Peacor, D. R.: Diagenesis and low-grade metamorphism of shales and slates, Rev. Mineral., 27, 335-380, 1992.

Pósfai, M. and Molnár, A.: Atmospheric aerosol particles: a mineralogical introduction, in: Environmental Mineralogy II, edited by: Vaughan, D. J., Wogelius, R. A., 213-293, European Mineralogical Union and the Mineralogical Society of Great Britain \& Ireland, London, 213-293, 2012.

Räisänen, P., Haapanala, P., Chung, C. E., Kahnert, M., Makkonen, R., Tonttila, J., and Nousiainen, T.: Impact of dust particle nonsphericity on climate simulations, Q. J. Roy. Meteor. Soc., 139, 2222-2232, 2013.

Reid, J. S., Jonsson, H. H., Maring, H. B., Smirnov, A., Savoie, D. L., Cliff, S. S., Reid, E. A., Livingston, J. M., Meier, M. M., Dubovik, O., and Tsay, S. C.: Comparison of size and morpho- 
logical measurements of coarse mode dust particles from Africa, J. Geophys. Res., 108, doi:10.1029/2002JD002485, 2003.

Ro, C.-U., Hwang, H., Kim, H., Chun, Y., and Van Grieken, R.: Single-particle characterization of four "Asian dust" samples collected in Korea, using low-Z particle electron probe X-ray microanalysis, Environ. Sci. Technol., 39, 1409-1419, 2005.

Seinfeld, J. H., Carmichael, G. R., Arimoto, R., Conant, W. C., Brechtel, F. J., Bates, T. S., Cahill, T. A., Clarke, A. D., Doherty, S. J., Flatau, P. J., Huebert, B. J., Kim, J., Markowicz, K. M., Quinn, P. K., Russell, L. M., Russell, P. B., Shimizu, A., Shinozuka, Y., Song, C. H., Tang, Y. H., Uno, I., Vogelmann, A. M., Weber, R. J., Woo, J. H., and Zhang, X. Y.: ACE-ASIA - Regional climatic and atmospheric chemical effects of Asian dust and pollution, B. Am. Meteorol. Soc., 85, 367-380, 2004.

Sokolik, I. N. and Toon, O. B.: Direct radiative forcing by anthropogenic airborne mineral aerosols, Nature, 381, 681-683, 1996.

Sokolik, I. N. and Toon, B. O.: Incorporation of mineralogical composition into models of the radiative properties of mineral aerosol from UV to IR wavelengths, J. Geophys. Res., 104, 9423-9444, 1999.
Sokolik, I. N., Winker, D. M., Bergametti, G., Gillette, D. A., Carmichael, G., Kaufman, Y. J., Gomes, L., Schuetz, L., and Penner, J. E.: Introduction to special section: Outstanding problems in quantifying the radiative impacts of mineral dust, J. Geophys. Res., 106, 18015-18027, 2001.

Środon, J.: Nature of mixed-layer clays and mechanisms of their formation and alteration. Annu. Rev. Earth Pl. Sc., 27, 19-53, 1999.

Tegen, I. and Lacis, A. A.: Modeling of particle size distribution and its influence on the radiative properties of mineral dust aerosol, J. Geophys. Res., 101, 19237-19244, 1996.

Vilaplana, R., Moreno, F., and Molina, A: Study of the sensitivity of size-averaged scattering matrix elements of nonspherical particles to changes in shape, porosity and refractive index, J. Quant. Spectrosc. Ra., 100, 415-428, doi:10.1016/j.jqsrt.2005.11.068, 2006.

Weaver, C. E.: Clays, muds, and shales, Elsevier, Amsterdam, 1989.

Zender, C. S., Bian, H., and Newman, D.: The mineral dust entrainment and deposition (DEAD) model: description and 1990s dust climatology, J. Geophys. Res., 108, 4416, doi:10.1029/2002JD002775, 2003. 